\title{
RELEVANCIA Y DESAFÍOS DEL PAISAJE EN LA FORMACIÓN DE UNA IMAGEN TURÍSTICA DE PRESTIGIO: LA COSTA DE LLANES (ASTURIAS)
}

\author{
Juan Sevilla Álvarez \\ Carmen Rodríguez Pérez. \\ Universidad de Oviedo
}

\section{RESUMEN}

La costa de Llanes (oriente de Asturias), enmarcada por el mar Cantábrico y la media montaña de la sierra del Cuera (apenas separados por 8 kilómetros), presenta rasgos paisajísticos singulares que han incentivado las visitas turísticas desde hace ya más de un siglo. Se trata de un espacio marcado por la trascendencia de los condicionantes naturales pero transformado en época reciente por la presión turística. En este trabajo se analiza el papel del paisaje en el desarrollo turístico, desde una perspectiva histórica, y se indaga en la capacidad de la propia actividad turística para transformar ese paisaje que, en origen, constituye un factor de atracción esencial. Siguiendo este cometido, se atiende a la evolución histórica de la divulgación del paisaje y se valoran los planteamientos de las acciones institucionales en lo relativo a la ordenación sectorial y territorial integral a distintas escalas.

Palabras clave: Paisaje, turismo, promoción, ordenación territorial, Llanes (Asturias, España).

The relevance and challenges of landscape in the construction of a prestigious tourist image: the coast of (East of Asturias, Spain)

\section{ABSTRACT}

The coast of Llanes, framed by the Cantabrian Sea and Sierra del Cuera mountains (barely separated by 8 kilometers), contains unique landscape elements that have stimulated tourist visits for more than a century. It is a space marked by the transcendence of natural conditions but transformed in recent times by tourist pressure. This paper analyzes the role of

Fecha de recepción: 16 de abril de 2018

Fecha de aceptación: 29 de octubre de 2018

Departamento de Geografía. Universidad de Oviedo. Campus del Milán. C/ Amparo Pedregal s/n. 33011 OVIEDO (España):E-mail: sevillajuan@uniovi.es, crperez@uniovi.es 
landscape in tourism development, from a historical perspective, and the posibility that tourism itself transform this landscape that, in origin, constitutes an essential factor of attraction. The historical evolution of landscape knowledge dissemination is presented as well as the approaches of institutional actions in sectoral and integral spatial planning at different scales.

Keywords: Landscape, tourism, promotion, spatial planning, Llanes (Asturias, Spain).

\section{INTRODUCCIÓN}

El paisaje se ha convertido en objeto de atención destacado en nuestra sociedad durante el período contemporáneo. Se ha revalorizado como un bien público a conservar en tanto que fuente de aprendizaje sociocultural, reflejo de prácticas colectivas e identidades territoriales, y elemento para el disfrute sensorial. Constituye un recurso de primer orden en el contexto de diversificación económica de los territorios que, aprovechando la difusión del hecho turístico en sus variadas modalidades, encuentran una alternativa para el desarrollo en la revalorización de sus rasgos territoriales y la prestación de servicios destinados a satisfacer la experiencia de los visitantes. Además, de acuerdo con esta nueva funcionalidad, y dadas las repercusiones y los potenciales conflictos generados por este fenómeno, el paisaje comienza a ser contemplado en acciones de ordenación y gestión, siendo muy distintos los ritmos de su integración en la práctica político-administrativa según los territorios y los planteamientos institucionales (Hernández Hernández, 2009).

La relación entre valoración del paisaje y desarrollo turístico parte, entre otros factores, de una motivación intrínseca al anhelo de viajar: la atracción y la curiosidad por lo inhabitual, lo inesperado o lo desconocido, y el contacto con espacios distintos de los cotidianos; en definitiva, el alejamiento de la rutina a través tanto de la percepción sensorial (principalmente visual, pero también auditiva, olfativa...) como de la práctica de actividades culturales, deportivas, de reposo, bienestar y salud, etc. en espacios singulares que despiertan diversos tipos de complacencia, entre ellas el sentimiento estético (Campo Francés, 1972; Callizo, 1993; Laguna Marín-Yaseli y Nogués Bravo, 2001; Aguilar Aguilar, Palafox Muñoz y Anaya Ortiz, 2015). El turista encuentra una respuesta a sus expectativas en la emoción causada por la contemplación del paisaje, en su experiencia de desplazamiento, visita y estancia en entornos distinguidos por la particularidad o excepcionalidad de aquél. La emoción está en el centro del comportamiento consciente del individuo en cualquier tipo de ambiente, participa de la interacción con el entorno en el que nos desenvolvemos; de ahí que el estado afectivo del turista constituya un indicador para comprender la valoración que hace de un espacio, de acuerdo con su experiencia en él (Ulrich, 1983; Delgado Martínez y Pantoja Timarán, 2016).

La preferencia por unos $\mathrm{u}$ otros lugares puede relacionarse, por tanto, con la percepción de cualidades y atributos tanto objetivos como ligados a un significado subjetivo del paisaje, de acuerdo con criterios compartidos por residentes y visitantes en su vivencia; aunque también inducidos por actores intelectuales e institucionales que se encuentran en el origen de la valoración (Zube, Sell y Taylor, 1982; Ormaetxea y Lucio, 1992; Lois 
González, Piñeira Mantiñán y Santomil Mosquera, 2010; Delgado Martínez y Pantoja Timarán, 2016). Se trata, en todo caso, de valores reconocidos y expresados de manera recurrente, que vienen a construir un imaginario del lugar: desde aquellos asociados a la representatividad, la excepcionalidad, la rareza o la escasez de elementos tangibles de tipo natural (geomorfológicos, climáticos, biogeográficos) y antrópico (artísticos, etnográficos), hasta los derivados de categorías estéticas (pintoresco, sublime...) y estados de ánimo ensalzados por corrientes de pensamiento contemporáneas (serenidad, sorpresa, entusiasmo, evasión, etc.); y también valores inmateriales que se relacionan con la memoria colectiva, vinculados a acontecimientos, tradiciones y modos de vida que han marcado el devenir de una sociedad.

Como portador de este conjunto de valores, el paisaje constituye un factor de desarrollo, en la base de la oferta y la demanda de actividad turística, en tanto que constitutivo de la imagen turística de un lugar. Esta imagen es fundamental pues condiciona la actividad de los agentes turísticos (permite diferenciar y posicionar su propuesta) así como los intereses y las decisiones de los visitantes (Campo Francés, 1972; Lois González, Piñeira Mantiñán y Santomil Mosquera, 2009 y 2010; Espejo Marín, 2011; Rivera Mateos, 2015).

Ahora bien, es necesario tener en cuenta la capacidad de atracción del paisaje y las acciones que en torno a él pueden surgir por parte de agentes interesados en rentabilizarlo de modo intensivo como objeto de consumo y fuente de riqueza, desplazando incluso a usos y actividades generadores del atractivo territorial original (Laguna Marín-Yaseli y Nogués Bravo, 2001; Aledo Tur, 2008; Hernández Hernández, 2009). Por ejemplo, en el contexto de desarrollo turístico español, sobre todo en el litoral y en áreas rurales con paisaje apreciado, no son extraños el exceso de oferta y los errores en las localizaciones, en los estilos arquitectónicos y en la introducción de medios técnicos, particularmente en el mercado inmobiliario, en la renovación de infraestructuras o en la oferta complementaria de bienes y servicios (Delgado Viñas, Gil de Arriba, Hortelano Mínguez y Plaza Gutiérrez, 2007; Lois González, Piñeira Mantiñán y Santomil Mosquera, 2009; Espejo Marín 2011; Aguilar Aguilar, Palafox Muñoz y Anaya Ortiz, 2015).

Es preciso, por tanto, adecuar los tipos y las intensidades de las actividades desarrolladas a las características del medio, de modo que no se degraden los valores distinguidos en origen; aquellos que contribuyen a la imagen turística del lugar transmitiendo el significado del paisaje como producto natural, histórico y social (Campo Francés, 1972; Vera Rebollo, 1992 y 1997; Salinas Chávez y Mateo Rodríguez, 1993). De lo contrario, se reduce el interés del lugar y a la postre, las posibilidades de desarrollo en torno a la nueva funcionalidad, deficientemente resuelta (Hernández Hernández, 2009). En efecto, el paisaje debe ser contemplado asimismo como un bien a administrar y preservar. Y el turismo debe encontrarse entre los sectores que lo protejan. Deben analizarse de forma sistemática la capacidad de atracción turística del paisaje y los potenciales riesgos como paso previo a una toma de decisiones integrada en la planificación, ordenación y gestión territorial (Salinas Chávez y Mateo Rodríguez, 1993; Cánoves et al., 2002).

En este artículo se presta atención a un espacio litoral que goza de alta consideración institucional y ciudadana por la diversidad y la particularidad de sus componentes naturales y culturales (Alvargonzález Rodríguez, 1997; Quirós Linares y Rodríguez Pérez, 1998). Se trata del municipio de Llanes, en el oriente de Asturias, flanqueado por el mar 
Cantábrico y la voluminosa sierra del Cuera. Sobre una estrecha franja que apenas alcanza 8 kilómetros en dirección N-S y aproximadamente 30 en dirección O-E se extiende un territorio singular que aúna valores geológicos, biogeográficos, estéticos, etnográficos, arqueológicos e histórico-artísticos con impronta paisajística muy apreciada en el conjunto de España y de la Europa atlántica. Un relieve accidentado, salpicado por el carst tanto en la plataforma costera como en la sierra del Cuera, sirve de asiento a yacimientos prehistóricos y protohistóricos, establecimientos eclesiásticos vinculados al Camino de Santiago, importantes edificaciones nobiliarias de la Edad Moderna así como suntuosas villas residenciales y lujosos equipamientos debidos al éxito ultramarino de los indianos, entre otros elementos del sector analizado.

La protección a través de figuras oficiales impulsadas desde distintas escalas y departamentos administrativos (Paisajes Protegidos, Monumentos Naturales, Bienes de Interés Cultural, Conjuntos Históricos, Zonas de Especial Conservación, etc.) no ha evitado el impacto de una presión turística creciente. De ahí el objetivo de analizar, al tiempo, el papel de paisaje en el desarrollo turístico y la capacidad de este sector de actividad para modificar el mismo paisaje que, en origen, se erige en factor de atracción. En las páginas que siguen nos fijamos en los rasgos distintivos de la costa de Llanes y exponemos cómo la nueva función turística genera una problemática territorial por la existencia de intereses y usos del suelo contrapuestos. Con la intención de desentrañar este proceso, analizamos cómo han evolucionado la divulgación y la promoción del paisaje llanisco, identificando los elementos y los valores del territorio que explican el origen y el posterior desarrollo de la actividad turística. A continuación, revisamos el tratamiento de tales elementos en los instrumentos de ordenación sectorial y territorial integral para reconocer algunas carencias, aunque también aciertos, en su adecuación a la especificidad del espacio analizado. El estudio conduce a una valoración final sobre un escenario no exento de conflictos pero con oportunidades para que la acción de los agentes territoriales converja hacia la correcta valorización del paisajeㄹ.

\section{LOS RASGOS DEL PAISAJE EN LA COSTA DE LLANES}

El paisaje de la costa de Llanes, en el oriente de Asturias, es el resultado de la combinación de unos factores físicos muy variados (relieve, condiciones climáticas, vegetación) y las actuaciones llevadas a cabo por el hombre sobre este espacio a lo largo del tiempo y que han tenido como resultado una modificación en ocasiones significativa de sus componentes, especialmente en lo tocante a la sustitución casi generalizada de las formaciones vegetales climácicas. Precisamente, la importancia que ha tenido la actuación humana secular sobre la naturaleza, algo que en realidad puede generalizarse a todo el sector costero cantábrico, implica que la utilización del término "paisaje natural" resulte en cierta medida inapropiado para referirse a un medio tan intensamente humanizado como el que

1 Este trabajo forma parte de los resultados del proyecto de investigación Diseño de un sistema de localización de fotografías aéreas históricas (España). Aplicaciones a la docencia, la investigación, el planeamiento y la ordenación del territorio (clave de referencia: cso2012-32428). Completa, además, la investigación llevada a cabo dentro de otro proyecto financiado en convocatoria estatal: Paisajes patrimoniales de la España atlántica y Navarra (clave de referencia: cso2012-39564-c07-05). Se utiliza, en este caso, un enfoque centrado en el estudio de la actividad turística. 
nos ocupa, aunque esto no contradice el hecho de que el armazón físico, y en especial, la organización del relieve, continúa trascendiendo de forma sustancial en su apariencia.

Un soporte natural que ha dirigido, en función de sus singulares rasgos topográficos y litológicos, tanto el aprovechamiento tradicional del terreno como la distribución del poblamiento y de las infraestructuras, modelándose un típico paisaje agrario de bocage, en el que la intercalación de parcelas de reducidas dimensiones y con distinta vocación productiva (prados, pomaradas, pequeños encinares, restos de bosquetes de frondosas,...), separadas entre sí por setos vegetales (sebes) de gran importancia para el mantenimiento de la biodiversidad animal y vegetal, conforman en conjunto una imagen con indudable atractivo turístico.

Sin embargo, este paisaje heredado ha experimentado un cambio radical en las últimas décadas inducido, en primer lugar, por la creciente presión de la función turística sobre este territorio y el creciente proceso urbanizador asociado a dicha actividad y, en segundo, por la expansión de un sistema de explotación forestal basado mayoritariamente en las repoblaciones con especies vegetales alóctonas de rápido crecimiento (Pinus pinaster y fundamentalmente Eucaliptus globulus)

\subsection{La trascendencia de los condicionantes naturales en la configuración del paisaje}

Este conjunto geográfico, perteneciente a la unidad geológica del Macizo Asturiano denominada región de Mantos, se caracteriza desde el punto de vista de su organización geomorfológica por la disposición escalonada y en el sentido de los paralelos de las unidades de relieve que lo integran, ofreciendo cada una de ellas, en función de su heterogeneidad litológica y de su evolución, una entidad marcadamente diferenciada (figura 1).

En su extremo meridional, la sierra del Cuera, alineación montañosa extendida de oeste a este a lo largo de unos 40 kilómetros, constituye el escalón superior de este sector costero, alcanzando su cota más elevada en el pico Turbina, con 1.315 metros de altitud. De naturaleza calcárea, su plataforma culminante ofrece una morfología irregular, encontrándose completamente acribillada por depresiones cerradas, en general de pequeñas dimensiones (dolinas, pozos nivales y sumideros), separados entre sí por relieves residuales de perfil cónico. En su vertiente septentrional, el enlace entre este cordal y el escalón inferior que integra este territorio, esto es, la marina o rasa costera, se establece a través de vertientes silíceas intensamente recortadas por el encajamiento torrencial, estando presente también en este sector de transición depresiones cerradas, algunas de dimensiones kilométricas como el polje de la Llosa de Viango (Frochoso y Castañón, 1990 a y b).

Como ya se ha indicado, hacia el norte de la sierra del Cuera y hasta alcanzar la línea de costa, se dispone la segunda de las unidades de relieve, correspondiéndose con una superficie prácticamente plana en toda su extensión -interrumpida únicamente por las hendiduras fluviales que la atraviesan- y que debemos entender deudora de la eficaz labor abrasiva llevada a cabo por el oleaje durante el período en que este sector permaneció sumergido. En todo caso y de manera coetánea al retroceso del mar y, sobre manera, con posterioridad, las plataformas de abrasión que quedaron emergidas fueron modeladas por procesos de tipo subaéreo, cambiantes a lo largo del tiempo en consonancia con las fluctuaciones climáticas que se han sucedido a lo largo del tiempo, y que han tenido una trascendencia desigual en función de los contrastes litológicos que se registran en este espacio (Flor, 1983). De esta 
manera, los niveles de abrasión marina se conservan en mayor medida sobre las hiladas de cuarcita armoricana y de arenisca que, extendidas de noreste a suroeste, conforman las sierras planas de Cué, La Borbolla o Pimiango, así como en las superficies llanas adosadas a la vertiente septentrional de la sierra del Cuera, situadas en conjunto a una altitud superior a los 100 metros, pudiendo ocasionalmente llegar a superar los 250 metros (Llano Reñances).

Figura 1

\section{ESQUEMA ILUSTRATIVO DE LAS DIFERENTES UNIDADES DE RELIEVE QUE INTEGRAN EL SECTOR ORIENTAL DE LA REGIÓN ASTURIANA (IMAGEN DE GOOGLE EARTH, 2015), EN EL QUE SE APRECIA SU DISPOSICIÓN EN EL SENTIDO DE LOS MERIDIANOS Y SU ORGANIZACIÓN ESCALONADA, DESCENDENTE EN DIRECCIÓN A LA LÍNEA DE COSTA}

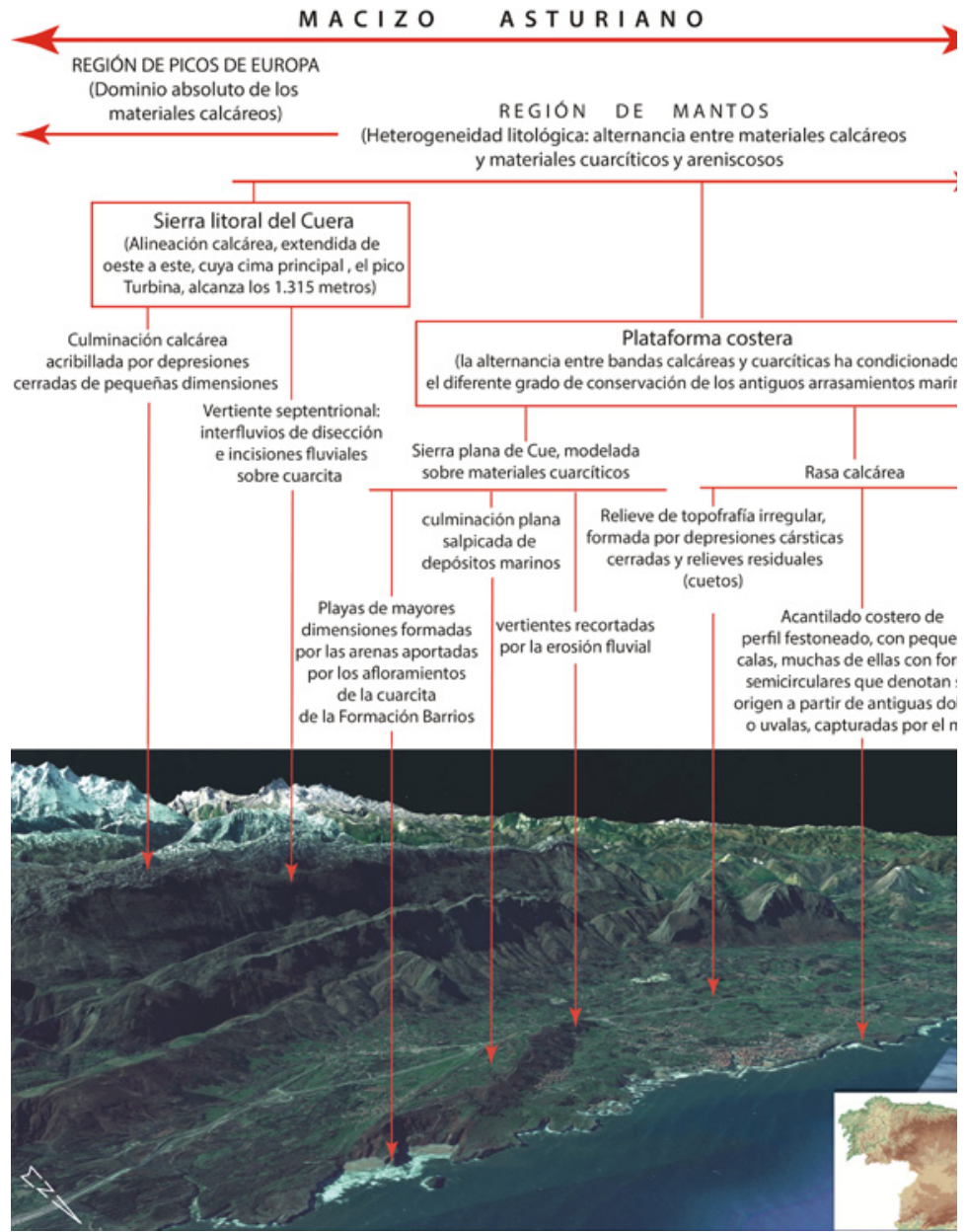


Por el contrario, allí donde la litología que conforma este territorio es de naturaleza calcárea se ha modelado una amplia superficie de corrosión cárstica que ofrece, a diferencia de los anteriores, además de una menor altura (inferior a 100 metros, conformando por tanto el escalón inferior de este conjunto geográfico), una morfología en detalle mucho más accidentada, resultado de la yuxtaposición, sin solución de continuidad, de dolinas, uvalas, pequeños vallejos y relieves cónicos residuales, a los que deben añadirse campos de lapiaz, surgencias, sumideros y bufones o bramadoiros, por los que el aire comprimido y el agua de mar son expulsados de forma violenta hacia el exterior con las mareas vivas y las galernas, constituyendo su funcionamiento un reclamo turístico de primer orden, tal como sucede con los localizados en Llames de Pría (figura 2) y los que horadan la rasa de Puertas de Vidiago (Romero López, 1984; Romero López y Sendín García, 1986).

\section{Figura 2}

\section{ACANTILADOS MODELADOS SOBRE LAS CALIZAS DE MONTAÑA DEL CARBONÍFERO, EN EL ENTORNO DE PRÍA. LA SUPERFICIE DE EROSIÓN CULMINANTE OFRECE UNA SUPERFICIE SUMAMENTE IRREGULAR AL ENCONTRARSE ACRIBILLADA POR LAPIACES Y HORADADA POR LOS CÉLEBRES BUFONES}

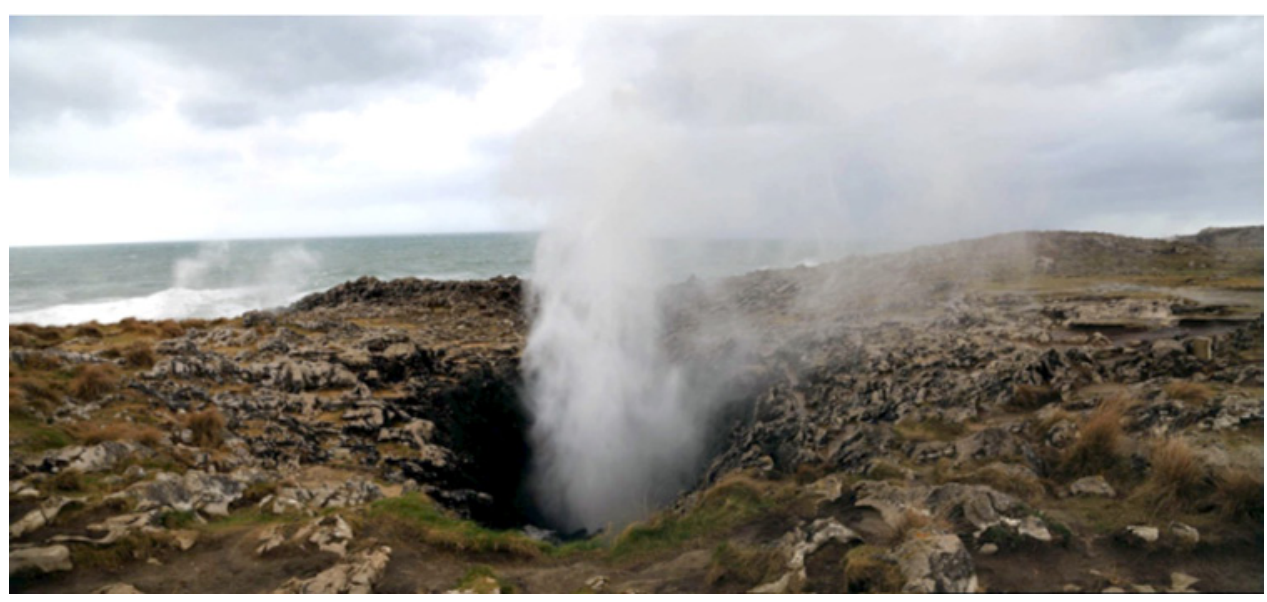

Fuente: Archivo fotográfico Víctor Fernández Salinas.

La red hidrográfica que drena este sector está integrada por un número escaso de ríos, siendo los más importantes los que, provenientes de la sierra litoral del Cuera, como es el caso del río de las Cabras o del río Purón, atraviesan perpendicularmente las estructuras del relieve. El resto de los cursos de agua son de corto recorrido, siendo bastante frecuente que el agua que transportan se pierda a través de sumideros abiertos en la caliza, pudiendo llegar a resurgir más adelante, poco antes de alcanzar ya la línea de costa.

Junto a los anteriores cabe resaltar, como elemento morfológico distintivo de la línea de costa de la marina oriental en el concejo llanisco, la existencia de numerosas calas de arena, en general de pequeñas dimensiones y acogidas en los entrantes del acantilado, que 
proporcionan a la línea de costa el perfil recortado que la caracteriza, aspecto que viene a reforzar la presencia de numerosos islotes, desgajados por la acción erosiva llevada a cabo por el mar, y que se conocen en la zona con el nombre de castros.

Por lo que concierne a otro aspecto fundamental de la configuración del paisaje, esto es, la cubierta vegetal, debe destacarse el hecho de que el aprovechamiento desarrollado por el hombre en este territorio ha tenido como consecuencia más visible una sustitución prácticamente generalizada de la vegetación original por áreas de prado y plantaciones forestales, fundamentalmente de eucalipto y de pino, perfectamente reconocibles en el paisaje por la coloración oscura que los caracteriza. De esta manera, las formaciones arbóreas naturales únicamente perviven en enclaves muy reducidos, en especial en torno a los cursos de agua que se han encajado en la rasa costera y en donde se conservan algunas alisedas y saucedas que, pese a sus reducidas dimensiones, tiene un gran interés ecológico.

Ahora bien, a pesar de la evidente merma en este sector costero de la que sería su vegetación planocaducifolia potencial (carbayedas de Quercus robur, asociados siempre con otras especies también de hoja caduca como fresnos, arces, olmos y tilos, en las áreas calcáreas, o abedules, en las silíceas), la existencia de un relieve accidentado en detalle, unido a la alternancia entre materiales calcáreos y silíceos, han posibilitado la conservación de un tapiz vegetal algo más variado que el que se puede observar en otras área de la marina cantábrica.

Así, en las vertientes de las sierras planas, de naturaleza silícea, se disponen amplias superficies de matorral recubiertas por la landa atlántica -favorecida en su desarrollo por los reiterados incendios que se han sucedido a lo largo del tiempo- entre las que se intercalan tanto pequeños bosquetes de carbayos y abedules, que prefieren suelos con óptimas condiciones de frescor y drenaje, como, ocupando las áreas más extensas, plantaciones forestales de eucaliptos. Los sectores culminantes de dichas sierras, por el contrario, y habida cuenta del perfil favorable de su topografía y del alto contenido en materia orgánico de los suelos aquí presentes, se encuentran ocupadas por prados de siega y parcelas de cultivo forrajero en su mayor parte, a excepción del uso terciario que se le ha dado a la sierra de Cué, asociado a la instalación de un campo de golf.

Más hacia el norte y hasta alcanzar la parte alta de los acantilados calcáreos, es decir donde ya no existe una influencia directa de la salinidad marina, los encinares, integrados por encinas (Quercus ilex), laureles (Laurus nobilis), madroños (Arbutus unedo), labiérnagos (Phillyrea angustifolia, Phillyrea latifolia) y aladiernos (Rhamnus alaternus), se suceden a lo largo de todo el litoral conformando bosquetes cerrados e impenetrables en virtud de la abundante presencia en su interior de plantas trepadoras (Lonicera periclymenum, Smilax aspera, Hedera helix, Rosa sempervirens, Tamus communis, ...) y de un sotobosque bastante denso y rico en especies.

Estas formaciones vegetales, asentadas más concretamente sobre los relieves residuales calcáreos de perfil cónico -conocidos con el nombre de cuetos- presentan, a pesar de encontrarse alejadas de su ámbito natural, un grado de conservación bastante aceptable debido a las favorables condiciones térmicas y edáficas de estos lugares escarpados, por otra parte no aptos, por esas mismas razones, para el aprovechamiento agrícola; esta particular adaptación explica la pervivencia en el tiempo de tales encinares, en tanto que los robledales o bosques mixtos caducifolios, que debieron colonizar en el pasado los espacios adyacentes, de menor inclinación y con suelos más profundos, han desaparecido 
prácticamente en su totalidad, dejando paso a otro tipo de aprovechamientos agrícolas (Blanco Castro et al., 1998).

La distribución actual de la vegetación se encuentra, por tanto, estrechamente vinculada a las actividades ganaderas y forestales que tradicionalmente se han desarrollado en este territorio y que han inducido al mantenimiento de un mosaico variado, en el que los cuetos, cubiertos por densos y enmarañados encinares o por plantaciones forestales con especies arbóreas alóctonas, se van alternando sin solución de continuidad con vaguadas y depresiones cársticas en las que comparten espacio los prados de siega, las pomaradas y las cada vez menos importantes tierras de cultivo, separados entre sí por sebes o lindes arboladas en cuya composición participan avellanos, saúcos, laureles, además de otras especies arbustivas.

\subsection{La dinámica del paisaje en el marco de la diversificación económica}

Una esmerada difusión del conocimiento de los atractivos naturales y culturales de la comarca oriental asturiana, a partir de la segunda mitad del siglo XIX, a través de obra científica, literaria, divulgativa y, además, mediante la progresiva edición de guías, o la promoción turística pública y privada, ha favorecido la consolidación de la actividad turística y el auge de la función residencial estacional en este sector. Con todo, su despegue llega durante la segunda mitad del siglo XX, principalmente en su último tercio, merced a la mejora de las comunicaciones, la generalización de los desplazamientos vacacionales en vehículos a motor particulares y a la proliferación de establecimientos de comercio, restauración, servicios de ocio y alojamiento en los núcleos más cercanos a las zonas de baño o paseo. Las actividades turísticas, junto a algunas industriales (agroalimentarias, de la madera y del mueble...) y a las del sector primario (pesqueras, ganaderas y forestales, sobre todo), se convierten en modeladoras de un paisaje progresivamente transformado, además, en la rasa, en las sierras planas y en los valles interiores por los problemas de viabilidad de la ganadería y el avance de las repoblaciones forestales con especies alóctonas, a costa de pastos, prados de siega y vegetación arbórea natural.

La presión por el uso del suelo se acentúa en los sectores más próximos al mar, a su vez los más accesibles por el paso de las principales vías de comunicación: la carretera nacional N-634, la Autovía del Cantábrico A-8 (finalizada a mediados de la presente década) y la histórica línea ferroviaria Oviedo-Santander (inicialmente perteneciente a Ferrocarriles Económicos y posteriormente integrada en FEVE), más lenta pero útil para los desplazamientos de proximidad a núcleos con atractivos turísticos. La accesibilidad juega a favor de la presión urbanística, al incrementar la demanda desde el centro de Asturias, Madrid, País Vasco y centro y noroeste de Castilla y León (Fernández y Sevilla, 2013).

En consecuencia, se observa en las últimas tres décadas una transformación de la morfología y la estructura del poblamiento tradicional debido al aumento de las segundas residencias en promociones individuales o en urbanizaciones, a la construcción de nuevas infraestructuras y a la adecuación de edificios preexistentes para la puesta en funcionamiento de alojamientos turísticos. Estas actuaciones densifican los núcleos y extienden el espacio urbanizado hacia la línea de costa, al margen de la red de caminos tradicional, recurriendo con frecuencia a tipologías y estéticas disonantes con la arquitectura tradicional, repetidos en otros territorios y que, por tanto, banalizan el paisaje. Se encuentran, sobre todo, en núcleos 
próximos al mar y bien dotados de servicios. Si se trata de pequeñas promociones, con un número reducido de edificaciones, pueden ubicarse en la parte central de pueblos y aldeas. Cuando las operaciones son mayores, se ubican en el exterior de estas pequeñas localidades. En ambos casos se intercalan entre parcelas con viviendas y actividades tradicionales y desarticulan el paisaje, aprovechando la favorable estructura parcelaria, muy fragmentada, y el retroceso de la ganadería (figura 3). Además, se benefician de una inadecuada gestión de los espacios dotados de valores patrimoniales, como se expone en apartados posteriores, sobre todo por la falta de coordinación entre escalas administrativas diferentes y políticas sectoriales o territoriales con incidencia paisajística (Hernández Hernández, 2009).

En la cabecera municipal, la terciarización y el crecimiento urbano han sido pronunciados debido a la prestación de servicios administrativos, sanitarios, sociales y educativos. Asimismo, se observa el auge de la función turística en la actividad del casco antiguo (Fernández García y Quirós Linares, 2001) y en la transformación del puerto para acoger embarcaciones recreativas. Ya en 1994 se había ampliado la antigua barra, reforzado la escollera y habilitado una zona de amarres deportivos en la dársena vieja. Más tarde, entre 2010 y 2012, se remodela en profundidad el puerto con el dragado de la dársena interior, la remoción de roca y arena y el aumento del calado; también se instalan pantalanes para acoger hasta 140 embarcaciones de recreo (figura 4). La obra no ha estado exenta de controversia por el desmontaje de la antigua compuerta y la supresión de diques históricos (Morales, 2012).

El desarrollo turístico conlleva asimismo problemas en los accesos a determinados lugares muy apreciados por los visitantes (playas, monumentos naturales...) debido a la alta frecuentación. En muchos casos, las visitas pierden valor al realizarse en un contexto de masificación o debido al acceso generalizado en vehículos a motor, que empobrecen y desnaturalizan la experiencia. Aparte, la vía de comunicación que mejora la accesibilidad, la autovía A-8, produce por sí misma un impacto ambiental y paisajístico acusado, alterando la calidad de los ecosistemas y de la percepción del paisaje, sobre todo en los tramos en que se aproxima más al mar. Afectan muy negativamente los desmontes realizados, las pantallas no vegetales y el ruido de la circulación. 
Figura 3

DINÁMICAS RECIENTES DEL PAISAJE DE LA COSTA ORIENTAL EN EL ENTORNO DE BARRO Y CELORIO (IMAGEN GENERAL DE GOOGLE EARTH). SE PERCIBE EL RETROCESO DE LA PRÁCTICA AGROGANADERA (IZQUIERDA) Y EL AVANCE DE LOS SERVICIOS DE ALOJAMIENTO TURÍSTICO (DERECHA)

Presencia de nuevos elementos en el paisaje como son los campings, vinculados a la creciente actividad turistica. En el año 1984 (imagen superior perteneciente al vuelo interministerial, fragmento del fotograma 4818) ya se había empezado a ocupar el camping de Maria Elena, en tanto que el de la Playa de Troenzo todavia no se había empezado a construir. En la imagen inferior, de 1989 (fragmento del fotograma 3462, perteneciente al Vuelo de Costas, 1989) ya se reconocen las dos instalaciones aunque el nivel de ocupación es muy inferior al actual.

Dinámica progresiva de la vegetación: invasión de las antiguas áreas de prado marginales por especies leñosas, motivada por la evolución reciente de la actividad agroganadera (fragmento del fotograma 3452. perteneciente al Vuelo de Costas, 1989).
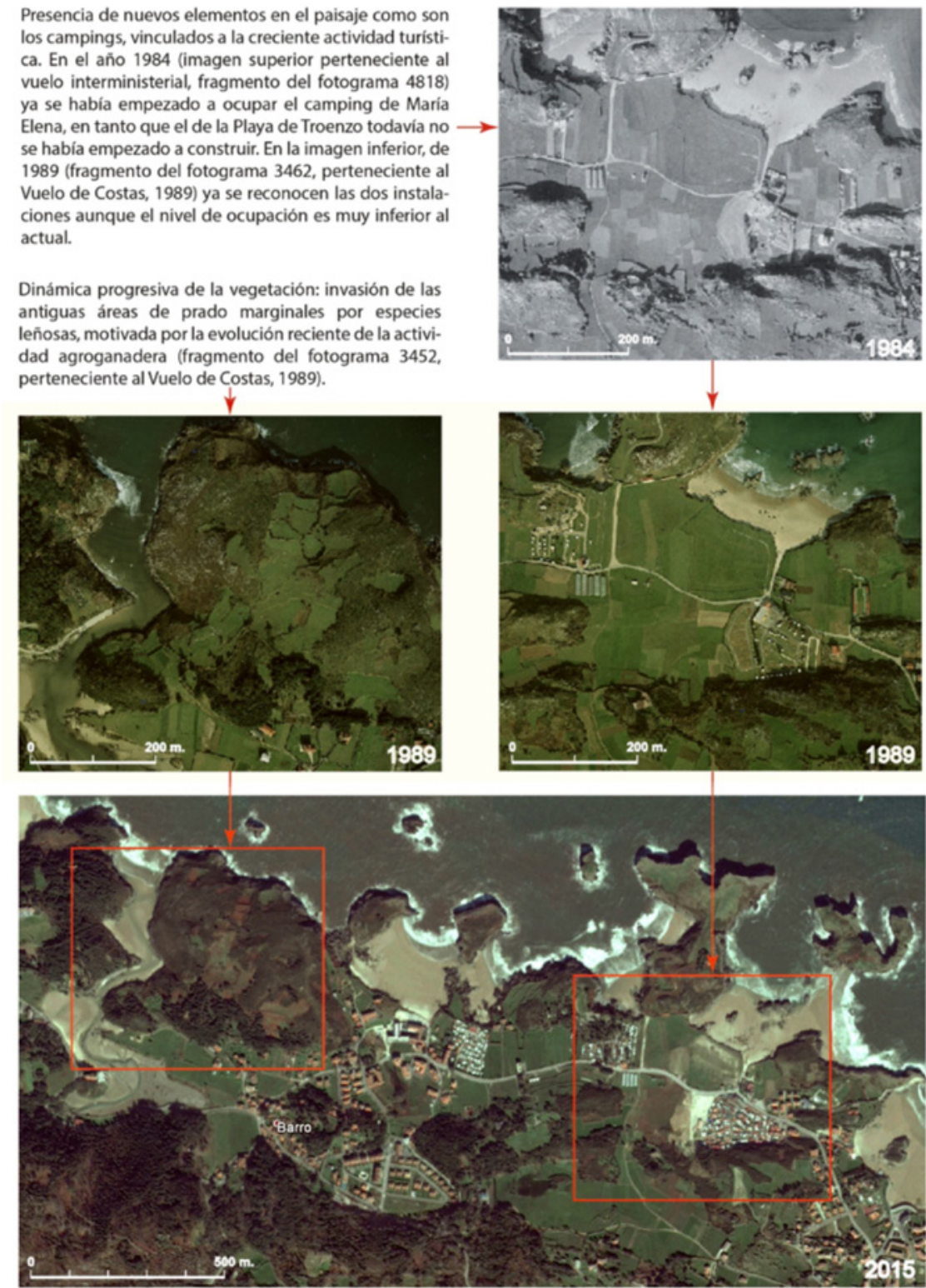

Cuadernos de Turismo, 43, (2019), 435-469 


\section{Figura 4 \\ TRANSFORMACIÓN DEL PUERTO PESQUERO DE LLANES EN PUERTO DEPORTIVO. IMAGEN HISTÓRICA DE 1915 Y RECIENTE DE 2018}
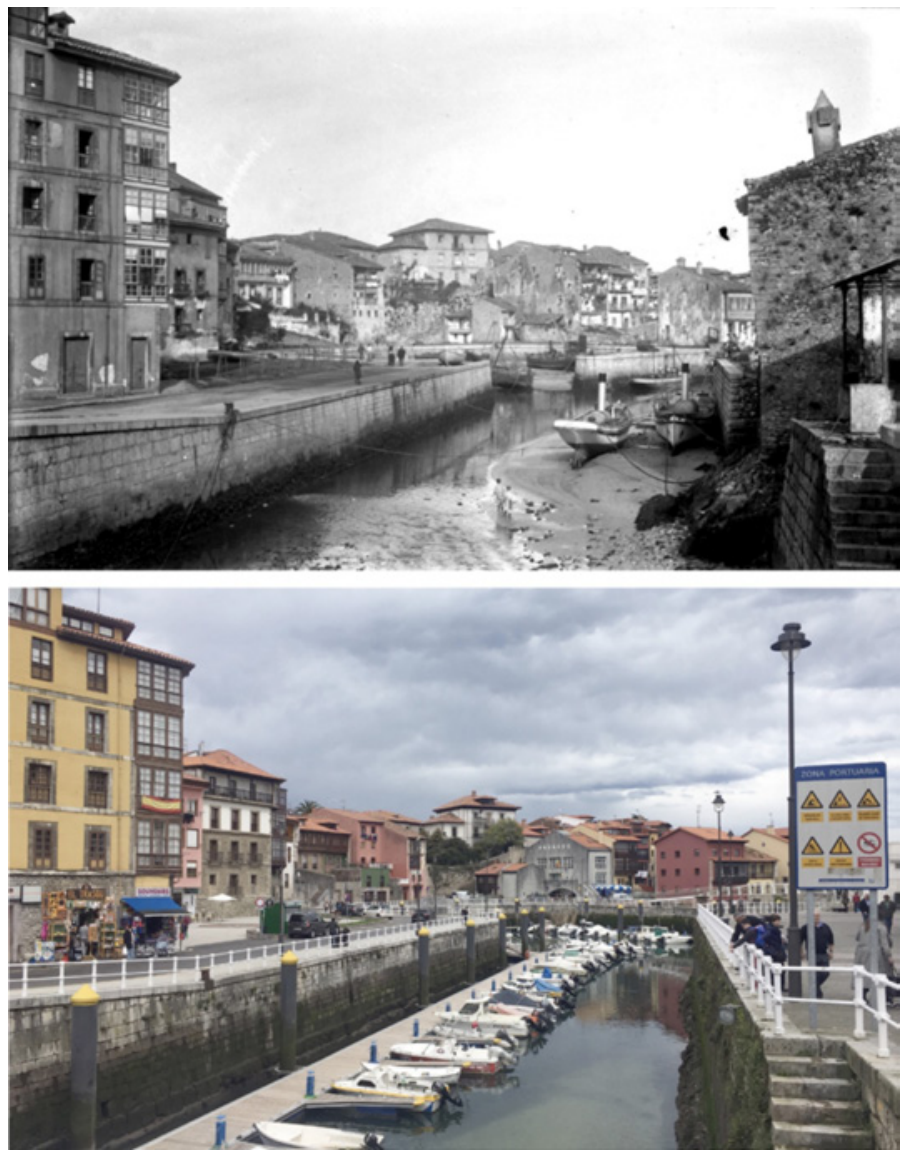

Fuente: 1915: https://www.asturias.es/portal/site/memoriadigital,_y reciente de 2018 los autores.

\section{EL PAISAJE COMO FACTOR DE ATRACCIÓN EN LA COSTA DE LLANES: DEL ORIGEN DE SU PUESTA EN VALOR AL DESAFÍO DE LA CONSERVA- CIÓN RECIENTE}

Con el fin de detallar el papel del paisaje en el desarrollo turístico y, al tiempo, poner en relación su dinámica reciente y los efectos de la actividad turística sobre el mismo, es pertinente conocer cómo surge y se difunde el aprecio por el paisaje del territorio estudiado, en qué medida la difusión del conocimiento de ese paisaje incentiva una corriente creciente de visitas, sobre todo a partir de la segunda mitad del siglo XIX y de manera generalizada a partir de mediados del siglo XX, y qué camino ha seguido la atención institucional, tanto 
desde la perspectiva de la promoción y planificación turística como desde las acciones para la protección y conservación de los elementos naturales y culturales singulares.

\subsection{La difusión del conocimiento del paisaje como factor en la formación de una imagen turística altamente valorada}

En el origen de la puesta en valor del sector costero del extremo oriental de Asturias como espacio de interés para la visita se encuentran las observaciones y los trabajos de viajeros, literatos, cronistas, artistas y científicos que, a través de su obra, atraen progresivamente la mirada de la sociedad y de los organismos oficiales. Uno de los hitos iniciales, aún alejado en el tiempo del despertar de la actividad turística, está en la caracterización que hace de la costa el cronista de Carlos V, Laurent Vital, en el relato de su primer viaje a España, en 1517. Tras su desembarco en Tazones el 19 de septiembre de dicho año, forzado por dificultosas condiciones para navegar, el emperador y sus acompañantes recorren la costa central y oriental, recogiendo la crónica del viaje una llamativa descripción de los rasgos de este territorio: explica la forma del puerto de Llanes, destaca las formas calcáreas del frente acantilado y llama la atención sobre el efecto visual y sonoro del agua al golpear y penetrar la roca horadada (Vital, 1958). Aparece ya entonces en los textos del cronista uno de los elementos más populares de esta costa: el patrimonio geomorfológico, particularmente sus célebres "bufones", denominación que se da a las salidas del agua a presión por la parte superior de la rasa, una vez agitada contra el frente costero y conducida a través de cavidades; también aparecen en las caracterizaciones los múltiples roquedos y los islotes desgajados del acantilado, allí denominados "castros".

Más tarde, al avanzar el siglo XIX y en los inicios del XX, la crónica local y la literatura vienen a favorecer la difusión del conocimiento de este territorio. Coincide con una etapa de prosperidad económica y dinamismo sociocultural a los que contribuye de manera notable el regreso de muchos "indianos" exitosos en su emigración ultramarina. Buena parte de ellos establecen nuevas villas residenciales, bien para períodos de reposo o definitivas, y apoyan la modernización de sus localidades de origen con la financiación de escuelas, infraestructuras básicas (alumbrado, abastecimiento de aguas, etc.) u otros equipamientos que acogen servicios asistenciales, lúdicos y culturales. La cabecera municipal toma un carácter urbano llamativo para los visitantes (Morales, 2011). Es entonces, además, cuando adquiere un desarrollo importante la prensa, principalmente con la fundación de El Oriente de Asturias, en 1868.

En estos medios de comunicación colaboran intelectuales ofreciendo noticias de toda índole para cubrir la crónica social, económica, política y cultural. No faltan las que divulgan acontecimientos históricos y los rasgos geográficos y etnográficos más singulares del lugar (Morales Saro, 1999); como las que aporta el jurista y escritor local José Saro Rojas, de quien debemos destacar la publicación de diecisiete fascículos dedicados a itinerarios de proximidad, entre 1886 y 1887 (posteriormente su hijo los agrupa en una obra titulada Pequeñas Jornadas). Es revelador el estilo empleado en muchas descripciones del paisaje, influido quizás por la corriente romántica y su sentimiento del paisaje; por ejemplo, el que impregna de entusiasmo el relato de la $2^{\mathrm{a} J}$ Jornada (junio de 1886). Saro recoge algunos de los elementos del paisaje que posteriormente otorgan a la costa oriental de Asturias su 
reputación: el sinuoso "festón" de la línea de costa, los cuetos encerrando las tierras de labor, el aspecto pintoresco de las localidades agraciadas con las construcciones "indianas" y, como fondo, la presencia voluminosa del Cuera.

El mismo sentimiento del paisaje va a aparecer en la obra de intelectuales extranjeros y de otras regiones españolas que visitan la zona; siendo Manuel de Foronda, natural de Ávila y miembro de la Sociedad Geográfica de Madrid, una figura fundamental en razón del itinerario De Llanes a Covadonga. Excursión geográfico-pintoresca, presentado en la Sociedad madrileña en 1884. Foronda inicia la excursión en el paseo de San Pedro, muy significativo desde la perspectiva de una conciencia de recreo incipiente por haber sido habilitado sobre el acantilado más occidental de la villa de Llanes en 1847 para el paseo y el disfrute del paisaje. Desde este lugar, dirige la mirada hacia el sur y divisa otro espacio de paseo, el de La Portilla. Y, por encima, contempla la muralla calcárea de la sierra del Cuera, interpuesta entre el mar y los Picos de Europa (Foronda, 1885). Sin dejar Llanes, villa de la que aporta notas sobre arquitectura (como hará más tarde al tratar las construcciones del medio rural), el abulense identifica la impronta indiana en el caserío y en el ambiente local. En el entorno de la cabecera municipal también destaca las peculiares formas de la caliza. De hecho, a Foronda se debe una curiosa comparación de los pináculos y conos modelados por la erosión marina en la playa de Toró con restos de edificaciones nobiliarias. Por otro lado, ofrece una explicación de las principales unidades de relieve de este sector litoral, sin duda llamativas por encontrarse tan próximas como contrastadas topográficamente.

Otro hito importante de este proceso de difusión del conocimiento del paisaje llanisco se encuentra en la estancia de José Zorrilla en Vidiago durante el otoño de 1882, como invitado de Manuel Lamadrid, indiano regresado de México. El poeta tiene la oportunidad de conocer los mismos lugares destacados por autores precedentes y encuentra inspiración para componer su célebre Cantar del Romero, en el que dedica varias estrofas a los bufones de los acantilados próximos a la localidad. En este contexto, mencionando al propio Zorrilla, toma relevancia otra figura significativa en este proceso, el padre Miguélez, por apoyar la actividad turística como oportunidad para el desarrollo de la comarca y reclamar una mejora de la red viaria y los alojamientos (Morales Saro, 1999). En aquella época, en efecto, se hacía común la visita de extranjeros interesados por las costumbres y tradiciones, la historia, el arte y la geografía de este territorio. Los textos y las representaciones gráficas divulgadas por ellos, véanse las del pintor Edgar T.A. Wigram en Northern Spain (1906), vienen a apuntalar la construcción de una imagen patrimonial claramente reconocible en la promoción turística posterior.

Aparecen en aquel momento muestras de una toma de conciencia creciente sobre las posibilidades turísticas de este sector en razón de la atracción que puede llegar a ejercer un marco natural y rural de elevada originalidad y belleza. En esta línea se puede considerar la Guía General del Viajero en Asturias (1899), de Octavio Bellmunt y Fermín Canella, obra pionera en la región por ofrecer información útil para el turista con un detalle que no se encuentra en las editadas por las casas extranjeras más prestigiosas (que abarcan un territorio mayor). El estilo es sencillo y directo, frecuente en trabajo de este género, al describir la costa como un territorio accidentado, salpicado de calas, puntas, islotes 
y pequeños abrigos de difícil acceso. Sin embargo, el relato adquiere un estilo distinto cuando ensalza la grandeza de la montaña levantada frente a la costa.

La Guía de Bellmunt y Canella marca el inicio de un género que tendrá ya cierta importancia al concluir el primer tercio del siglo XX. Le sigue la Guía General de Asturias para 1905, de José Gutiérrez Mayo y Gerardo Álvarez Uría, donde podemos destacar, entre otras, la referencia al patrimonio construido y a las infraestructuras financiadas por los indianos. Posteriormente, Asturias, paraíso del turista (1925), de Antonio Pérez y Pimentel reafirma la alta consideración del patrimonio geomorfológico destacando las playas de Toró y de Cuevas del Mar por la belleza del roquedo, de pináculos en una y galerías y arcos naturales en la otra. Asimismo, menciona el "famoso bufón descrito por Zorrilla" en su descripción de la costa, de la que destaca el número de playas que, ya en esta época, son concurridas. Además, al igual que otros autores de guías, llama la atención sobre la animación cotidiana que proporciona la comunidad de acaudalados emigrantes que han hecho las Américas (Pérez y Pimentel, 1925).

En ese tiempo la apuesta por el turismo avanza con iniciativas muy significativas, como lo demuestra la creación del aeródromo destinado a la aviación deportiva a comienzos del siglo XX sobre la sierra plana de Cué (sustituido recientemente por un campo de golf; véase Fernández García y Quirós Linares, 2001). Destaca también la idea de proyectar un conjunto de chalés en la cabecera llanisca, en el campo de San Antón, a modo de reclamo para la población no local; se debe al Marqués de Argüelles y tiene lugar en 1908. A partir del año siguiente se consolida con actuaciones como el nuevo Casino, de estilo ecléctico, cuya construcción es promovida por la Sociedad del Casino de Llanes con aportaciones indianas; o el Teatro Benavente, que se inaugura en 1924 e impulsa la programación cultural de la villa con actuaciones de destacadas compañías nacionales (Morales, Álvarez y Valle, 2003).

Se busca promocionar, de esta forma, una imagen de calidad que poco a poco encuentra respuesta en familias de la propia región, de las limítrofes o de Madrid, además de los indianos que regresan de América. El aumento de las visitas se percibe en el alquiler de pisos durante períodos estivales, pero también en la construcción de chalets (Ferrer Regales, 1963).

En el extranjero, la incipiente imagen turística de la marina oriental asturiana aparece en publicaciones como la célebre Guide Bleu de Hachette, que empieza a incluir informaciones con mayor detalle. Podemos señalar, por ejemplo, la referencia de la edición de 1927 al ídolo de Peña Tú, singular peñasco localizado sobre las sierras planas en Puertas de Vidiago, especialmente valioso por la incisión de figuras humanas e instrumentos grabados en época neolítica (Monmarché (Dir.), 1927). La reseña de Hachette coincide con la recomendación de Aurelio del Llano en Bellezas de Asturias, de Oriente a Occidente (1928) del mismo ídolo, probablemente conmemorativo y funerario. Precisamente, en las páginas de Aurelio del Llano se consolida la formación de una imagen turística del oriente litoral asturiano con numerosas menciones a elementos destacados por los intelectuales anteriormente citados: el puente de Santiuste y su posición sobre la playa de La Franca, el bufón de Vidiago, los panoramas privilegiados a disfrutar desde paseos y miradores, la erguida sierra del Cuera y, en general, la vida veraniega y el ocio de "forasteros" en las localidades costeras (Llano Roza de Ampudia, 1928). 


\section{Cuadro 1 \\ MUESTRA DEL RECONOCIMIENTO INTELECTUAL E INSTITUCIONAL}

\begin{tabular}{|c|c|}
\hline Lugar & Referencias \\
\hline $\begin{array}{l}\text { Acantilados } \\
\text { de Puertas de } \\
\text { Vidiago }\end{array}$ & $\begin{array}{l}\text { - "[...] festoneando la tierra firme el mar en toda su grandeza [...]” (Saro } \\
\text { Rojas, edición de } 1985 \text {-original de 1886-). } \\
\text { - “[...] Después de pasar por el pueblo de Puertas se camina a través de una } \\
\text { meseta de caliza. Y a setenta metros del mar, se encuentra un pozo al cual se } \\
\text { puede bajar con facilidad. En su centro tiene un agujero que es el extremo } \\
\text { acodado de un embudo subterraneo cuya boca se abre en el tajado cantil [...]” } \\
\text { (Llano Roza de Ampudia, 1928). } \\
\text {-“[...] el roquedo calizo ha sufrido procesos de disolución kárstica, dando lugar } \\
\text { a un sinfín de formas de relieve que confieren al área una singular belleza. [...] } \\
\text { las calizas, por otra, han adoptado nuevas formas vinculadas a su capacidad } \\
\text { para disolverse por acción del agua y aparecen formando dolinas, lapiaces, si- } \\
\text { mas, cuetos, cuevas y otras formaciones, que confieren un aspecto sumamente } \\
\text { atractivo y singular al territorio [...]” (Principado de Asturias, s.f. a). } \\
\text {-Paisaje de Interés Cultural de Asturias: F. Referentes geográficos } \\
\text { connotados. F.1. Relacionados con el agua. F.1.3. Litorales” (Fernández } \\
\text { Salinas, 2013). } \\
\text {-Escenario en obra cinematográfica: El abuelo, de José Luis Garci, } 1998 \\
\text { (Ayuntamiento de Llanes, s.f. a). }\end{array}$ \\
\hline $\begin{array}{l}\text { Cementerio } \\
\text { de Niembro y } \\
\text { ría de Barro }\end{array}$ & $\begin{array}{l}\text {-Paisaje de Interés Cultural de Asturias: "E. Sistemas de creencias, artes y } \\
\text { comunicación.E.1. Ritual.E.1.2. Culto y rito funerario"(Fernández Salinas, 2013). } \\
\text {-Escenario en obras cinematográficas: Epílogo, de Gonzalo Suárez, 1984; } \\
\text { El abuelo, de José Luis Garci, 1998; La Señora, serie de Lluis María Güell, } \\
2008 \text { (Ayuntamiento de Llanes, s.f. a). }\end{array}$ \\
\hline $\begin{array}{l}\text { Centro histórico } \\
\text { de Llanes }\end{array}$ & $\begin{array}{l}\text { - "[...] las capillas de San Roque y de la Magdalena, y otros muchos edificios } \\
\text { de destacada valía que prestan singular fisonomía a la villa de Llanes [...]" } \\
\text { (Gobierno de España, 1971). } \\
\text {-Paisaje de Interés Cultural de Asturias: "A. Sistema de asentamiento. } \\
\text { A.2. Dominante urbana. A.2.2. Ciudades y villas de tradición medieval y } \\
\text { moderna" (Fernández Salinas, 2013). } \\
\text {-Escenario en obra cinematográfica: Historia de un beso, de José Luis Garci, } \\
2002 \text { (Ayuntamiento de Llanes, s.f. a). }\end{array}$ \\
\hline $\begin{array}{l}\text { Estación de } \\
\text { Posada de } \\
\text { Llanes }\end{array}$ & $\begin{array}{l}\text {-“[...] atraviesa el concejo la carretera de Torrelavega a Oviedo con coches } \\
\text { de linea hasta Arriondas a enlazar con el FFCC de Oviedo a Santander } \\
\text { cuyas obras (del tramo) de Arriondas a Llanes estàn muy adelantadas [...]" } \\
\text { (Gutiérrez Mayo y Álvarez Uría, 1905). } \\
\text {-“[...] La animación de la vida maritima fue sustituida por la que el FFCC } \\
\text { trae a diario a la capital del Oriente astur. Término de los Economicos y del } \\
\text { Cantàbrico, numerosos trenes la cruzan a diario [...]” (Pérez y Pimentel, 1925). } \\
\text {-Escenario en obras cinematográficas: Epílogo, de Gonzalo Suárez, 1984; El } \\
\text { abuelo, de José Luis Garci, } 1998 \text { (Ayuntamiento de Llanes, s.f. a). }\end{array}$ \\
\hline
\end{tabular}




\begin{tabular}{|c|c|}
\hline Lugar & Referencias \\
\hline $\begin{array}{l}\text { Paseo de San } \\
\text { Pedro en Llanes }\end{array}$ & $\begin{array}{l}\text {-“[...] lo grandioso del espectáculo que la naturaleza nos ofrece, recompensa } \\
\text { sobradamente lo largo del viaje [...]. Observad al O. la cadena de montañas } \\
\text { que interponen sus elevadas cumbres entre nosotros y las famosas cimas de } \\
\text { Covadonga [...] (Foronda, edición de } 1993 \text { - original de 1885-). } \\
\text {-“[...]...trazado a lo largo del abrupto cantil, donde la naturaleza nos ofrece } \\
\text { un cuadro grandioso [...]. Paralelamente al mar se yergue la sierra del Cuera } \\
\text { envuelta en un velo de niebla luminosa; y se extiende el valle risueño, entre } \\
\text { cuya arbolada se ven casitas blancas y elegantes hoteles que alquilan los } \\
\text { forasteros que vienen a veranear a este delicioso pais. Y abajo, al pie del } \\
\text { paseo, la villa señoril [...]” (Llano Roza de Ampudia, 1928). } \\
\text {-Escenario en obra cinematográfica: Historia de un beso, de José Luis Garci, } \\
2002 \text { (Ayuntamiento de Llanes, s.f. a). }\end{array}$ \\
\hline $\begin{array}{l}\text { Playa de Cuevas } \\
\text { del Mar }\end{array}$ & $\begin{array}{l}\text {-“[...] Dejando a la izquierda Cuevas del Mar, de bonitas grutas y concurrida } \\
\text { playa [...]”.(Pérez y Pimentel, 1925). } \\
\text {-«[...] La paroi occidentale montre neuf gisements de galets de grès cimentés } \\
\text { par du travertin associés à des cavités karstiques aménagées par la mer. La } \\
\text { paroi orientale [...] Elle est percée de trois ouvertures ogivales donnant à } \\
\text { l'ensemble l'allure d'un pont inachevé [...]"(Mary, 1979 y 1983). } \\
\text {-“[...] "las calizas, por otra, han adoptado nuevas formas vinculadas a su capaci- } \\
\text { dad para disolverse por acción del agua y aparecen formando dolinas, lapiaces, } \\
\text { simas, cuetos, cuevas y otras formaciones, que confieren un aspecto sumamente } \\
\text { atractivo y singular al territorio [...]" (Principado de Asturias, s.f. a). } \\
\text {-Escenario en obra cinematográfica: You're the one, de José Luis Garci, } 2000 \\
\text { (Ayuntamiento de Llanes, s.f. a). }\end{array}$ \\
\hline $\begin{array}{l}\text { Playa de Toró } \\
\text { y acantilado }\end{array}$ & $\begin{array}{l}\text {-“[...] Arcos que todavía se mantienen de una manera inverosímil, macizas } \\
\text { columnatas truncadas irregularmente casi a la mitad de su altura...trozos } \\
\text { de construcción que revelan la existencia de notable anfiteatro...todo esto } \\
\text { creeréis ver, todo esto veréis a poco que os dejéis llevar de vuestra fantasía en } \\
\text { la playa de Toró [...]" (Foronda, 1885). } \\
\text {-Asturias, paraíso del turista: "Sería interminable detallar las playas [...]. } \\
\text { La de Toro, de bonitas rocas y curiosas rompientes [...]" (Pérez y Pimentel, } \\
\text { 1925). } \\
\text {-“[...] La captura de las dolinas da lugar a playas como la de Toró o bahías } \\
\text { como la de Niembro [...]" (Principado de Asturias, s.f. a). } \\
\text {-Escenario en obras cinematográficas: Aoom, de Gonzalo Suárez, 1970; Una } \\
\text { gloria nacional, serie de Jaime de Armiñán, 1993; El detective y la muerte, } \\
\text { de Gonzalo Suárez, 1994; El abuelo, de José Luis Garci, 1998; La balsa de } \\
\text { piedra, de George Sluizer, } 2002 \text { (Ayuntamiento de Llanes, s.f. a). }\end{array}$ \\
\hline
\end{tabular}

Fuente: elaboración propia a partir de las fuentes citadas en el cuadro.

Se puede ver como en el contexto de difusión de la práctica del baño de ola, de la excursión de proximidad o del viaje con fines culturales, las primeras guías turísticas 
recogen y completan progresivamente las informaciones de obras precedentes sobre rutas y sitios, contribuyendo de este modo a una valoración patrimonial de indudable interés turístico donde los parajes son distinguidos como óptimos para la contemplación, el descanso, el ocio y el aprendizaje cultural. Todo ello tiene reflejo en el crecimiento del turismo extranjero (franceses e ingleses, sobre todo) y el aumento del número de establecimientos hoteleros, aunque de capacidad limitada y con funcionamiento estacional, que se completa con el alquiler de viviendas. En Llanes, en 1942, se suman dos hoteles al que ya existía mientras que, en las localidades próximas, en época de posguerra, también se produce la apertura de hoteles y se registra la construcción de chalets. Por otro lado, es significativo el traspaso de la propiedad de algunas casas nobiliarias a profesionales acomodados residentes en las ciudades asturianas o en Madrid. Aparte, igualmente relacionada con el fenómeno aquí estudiado, con ayuda de la emigración ultramarina, es la existencia de dos sucursales de agencias de viajes y de cinco sucursales bancarias (Ferrer Regales, 1960).

Se forma así una imagen que se repetirá sucesivamente en nuevas ediciones de obras de divulgación y vendrá a articular las acciones de promoción turística de los organismos oficiales en las décadas siguientes: como, por ejemplo, las llevadas a cabo por la Dirección General de Promoción del Turismo, la Diputación de Oviedo, el Centro de Iniciativas y Turismo del Oriente de Asturias, y posteriormente el Gobierno del Principado de Asturias, con la correspondiente Consejería y la Sociedad Pública de Gestión y Promoción Turística y Cultural. Asimismo, deben mencionarse las actuaciones desarrolladas por el Ayuntamiento de Llanes, muy activo desde un primer momento.

Las entidades responsables de la promoción turística engloban los valores naturales y culturales en una actuación que refuerza progresivamente el interés de la visita a través de iniciativas y actividades que atraen a la población hacia los enclaves e itinerarios históricamente apreciados y divulgados. Las visitas aumentarán, además, desde el momento en que se generalizan las vacaciones en distintos sectores de la población (ya no solamente los económicamente acomodados) y, muy notablemente, cuando se extiende el uso del automóvil particular. Contribuye a ello, por otro lado, la disminución del tiempo de viaje desde el área central de Asturias y desde fuera de la región, constante desde la década de 1960, con la mejora de la red de carreteras nacionales, la construcción de autopistas, el aumento del tráfico aéreo en los aeropuertos asturiano y cántabro, además de la llegada de líneas de ferry desde diversos puertos atlánticos. Al mejorar la accesibilidad, crece la frecuencia de las estancias cortas, lo que impulsa la oferta de alojamientos de diverso tipo: campings, albergues, apartamentos y casas de alquiler, hostales, hoteles, etc. Del mismo modo, crece la población que, sin vínculo inicial con la comarca o con vínculo, pero regularmente desplazados a otras áreas, buscan una segunda residencia para fines de semana y períodos vacacionales. 


\section{Figura 5 \\ PLAYA EN CELORIO, DESDE EL TABÁN, EN 1960. LA FOTOGRAFÍA SE EMPLEÓ PARA LA PROMOCIÓN TURÍSTICA DEL CONCEJO DE LLANES. FOTO Y EDICIÓN DE RAMÓN ROZAS, LLANES}

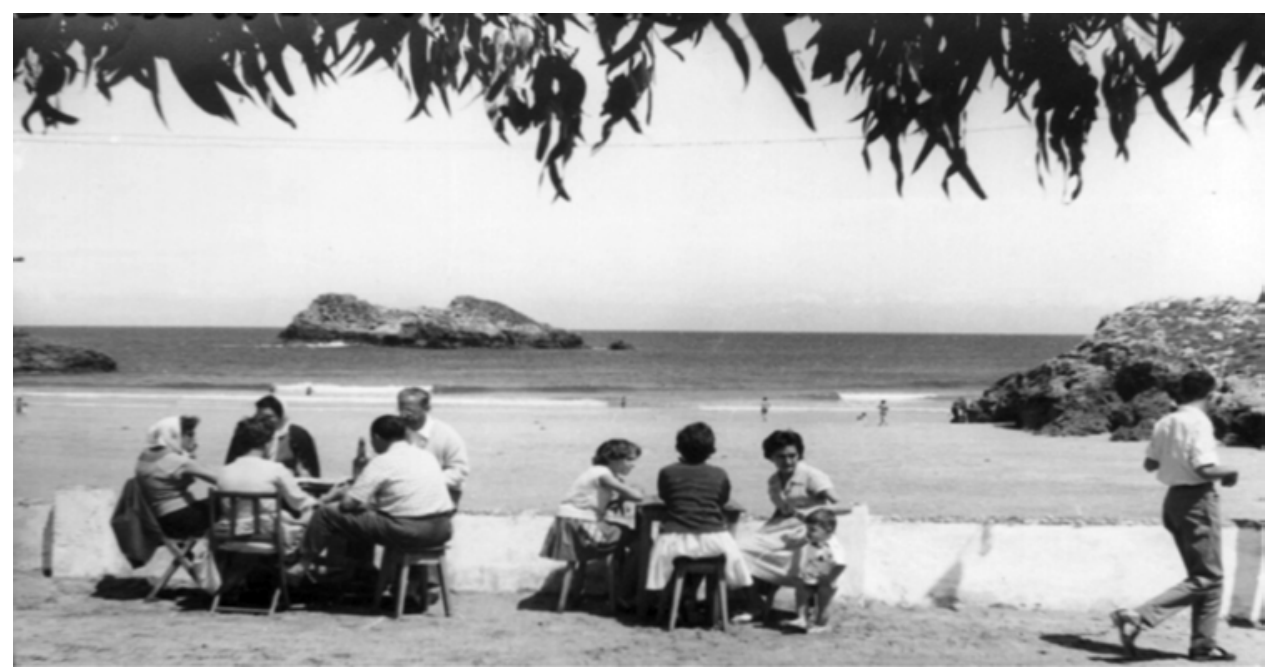

Fuente: Archivo Autonómico Institucional (https://www.asturias.es/portal/site/memoriadigital).

Así, por ejemplo, llegando a finales de la centuria, concretamente en 1997, se contabilizan 40.492 visitantes en la Oficina de Turismo del Ayuntamiento de Llanes; en ese mismo año se ofertan ya 9.441 plazas de alojamiento turístico en el mismo municipio (Ayuntamiento de Llanes, 2018), lo que refleja un sensible aumento respecto a las modestas cifras señaladas para mediados de siglo, continuando la tendencia al incremento de la oferta en los años siguientes (cuadro II). De acuerdo con la información recogida en el Sistema de Información Turística de Asturias, entre las principales razones de la elección de este concejo como destino turístico se encuentran la riqueza del entorno natural y cultural $(18,8 \%)$, la experiencia de visitas anteriores $(12,5 \%$, seguramente positivas por la misma razón anterior), la tranquilidad del lugar $(8,4 \%)$, la gastronomía $(7 \%)$, el clima benigno $(4,7 \%)$ o la ausencia de masificación turística $(4,5 \%)$, aspectos, todos ellos, asociados a la singularidad geográfica. Ocurre de modo similar con las actividades contratadas, entre las que sobresalen las excursiones a caballo $(14,3 \%)$, el senderismo $(13,3 \%)$, las visitas a artesanos $(10,9 \%)$, las actividades acuáticas $(7,9 \%)$ o el alquiler de bicicletas $(4 \%)$, entre otras. Avanzada la primera década del presente siglo, se mantienen en buena medida algunas razones de la elección del destino: entorno natural $(19,3 \%)$, conocer nuevos lugares $(18,3 \%)$, experiencia anterior $(17,8 \%)$, gastronomía $(9,4 \%)$, recomendaciones $(8 \%)$, tranquilidad $(7,4 \%)$ y patrimonio cultural $(5,8 \%)$. Entre las actividades realizadas, y en relación con el tema tratado, destacan las visitas a pueblos y lugares (68\%), ir a la playa $(60,8 \%)$, visitar monumentos $(47 \%)$, visitar museos $(15,7 \%)$, ir a la montaña $(10 \%)$, 
realizar actividades de turismo activo $(9,6 \%)$ o realizar rutas cortas de senderismo $(8 \%)$ (SITA, s.f. a).

\section{Cuadro 2}

\section{PLAZAS Y ESTABLECIMIENTOS DE ALOJAMIENTO COLECTIVO, POR TIPO, EN LLANES (2004)}

\begin{tabular}{|c|c|c|}
\hline Tipo/Categoría & $\mathrm{N}^{\circ}$ de plazas & $\mathrm{N}^{\mathrm{o}}$ de establecimientos \\
\hline Hoteles 4 estrellas & 62 & 1 \\
\hline Hoteles 3 estrellas & 924 & 21 \\
\hline Hoteles 2 estrellas & 717 & 29 \\
\hline Hoteles 1 estrella & 291 & 12 \\
\hline Hostales & 91 & 2 \\
\hline Pensiones & 312 & 20 \\
\hline Hoteles rurales & 133 & 5 \\
\hline Casas de aldea & 635 & 89 \\
\hline Apartamentos rurales & 138 & 8 \\
\hline Camping & 7.866 & 10 \\
\hline Apartamento turístico & 663 & 28 \\
\hline Albergue & 816 & 10 \\
\hline Viviendas vacacionales & 78 & 12 \\
\hline TOTAL & 12.726 & 247 \\
\hline
\end{tabular}

Fuente: Sistema de Información Turística de Asturias, s.f. b.

En esta época, la generalización de la planificación turística a diferentes escalas administrativas tiene importancia en la región asturiana y, de modo especial, en la costa oriental, siendo el paisaje objeto de tratamiento en los documentos técnicos elaborados, de modo más explícito o implícito, según los planteamientos desarrollados. En mayo de 1995 se firma un convenio marco de colaboración para la implantación de un Plan de Excelencia Turística en Llanes, entre el Ministerio de Comercio y Turismo, la Consejería Industria, Turismo y Empleo del Principado de Asturias, el Ayuntamiento de Llanes y las asociaciones empresariales con intereses turísticos en dicho concejo, en la línea establecida por el Plan Marco de Competitividad del Turismo Español (Plan FUTURES). Se trataba 
de incrementar la calidad de los destinos en aspectos relacionados con factores medioambientales, de modo que repercutiera positivamente en la percepción y satisfacción de los visitantes, aparte de otros objetivos (desestacionalización, diversificación de la oferta, adecuación de los productos turísticos a las tendencias en la demanda...). Las áreas de actuación preferente incluían aspectos como la mejora del entorno urbano, la creación, ampliación y mejora de los espacios de uso público y el cuidado del medio ambiente. Con el fin de aplicar el Plan de Excelencia, el Ayuntamiento se comprometía a hacer ejercicio de sus competencias para mejorar la limpieza y el cuidado del entorno, y evitar el crecimiento incontrolado de los núcleos urbanos a través de instrumentos de planeamiento urbanístico que tuvieran en consideración crecimientos limitados y acordes con el cuidado medioambiental (Ayuntamiento de Llanes, 1995).

Posteriormente, se redacta el Estudio para la formulación de iniciativas turístico pesqueras en el municipio de Llanes (2008) con una introducción al entorno geográfico que subraya la importancia de los componentes naturales, con especial atención al relieve, y antrópicos del paisaje, haciendo hincapié en los derivados de la actividad pesquera y sus infraestructuras, como factor para la distinción y singularidad de este destino turístico. Se caracterizan algunos recursos territoriales de especial interés para la diversificación turística vinculada con la pesca y que tienen que ver con la valoración del paisaje litoral como los paseos de San Pedro y San Antón, el puerto, el faro, el tendedero de redes, la lonja, la capilla de Santa Ana (patrona de los pescadores), principalmente. Este estudio persigue configurar un eje de recursos turísticos temáticos del que se destaca su interés paisajístico, acompañado de su valor arquitectónico, cultural y etnográfico (Ayuntamiento de Llanes, 2008). Estos y buena parte de los recursos ya mencionados, relacionados con espacios y actividades turísticas variadas en el litoral de Llanes, vuelven a aparecer recogidos como esenciales en el Programa de Turismo Sostenible del Principado de Asturias 2020, insistiendo en la dimensión paisajística como valor diferencial, además de elemento constitutivo de la sociedad asturiana y sus promotores turísticos (Principado de Asturias, s.f. c).

En ese contexto de desarrollo turístico a través de planificación y gestión de los destinos, aparecen iniciativas turísticas con participación municipal, autonómica y estatal en torno a elementos naturales y culturales que han marcado el devenir de la comarca oriental de Asturias y dan forma al paisaje: se abren el Aula del Mar en Llanes (2000), el Museo Etnográfico del Oriente de Asturias en el conjunto arquitectónico tradicional de Porrúa (2000) o el Aula Didáctica de Peña Tú en Puertas (comienza la obra en 2002). También se adecua la plataforma de la sierra plana de Cué para la práctica del golf (1989, ampliado en la década siguiente -figura 6-) así como el puerto llanisco para embarcaciones deportivas (2012). Muy significativa es, por otro lado, la apuesta por el arte público como nexo entre la población y lugares convertidos en hitos paisajísticos. En este sentido sorprende la obra "Los Cubos de la Memoria" de Agustín Ibarrola (2000-2002), en la nueva escollera del puerto de Llanes. Su composición desborda las aristas de 300 planos de cubos de hormigón para dibujar formas y volúmenes que evocan, de manera simbólica, la historia y la identidad de la villa (Morales, 2011; Álvarez Martínez, 2015). 


\section{Figura 6 \\ VISTA DE LA CULMINACIÓN DE LA SIERRA PLANA DE CUÉ, SOBRE LAS PLAYAS DE BALLOTA Y ANDRÍN. SE APROVECHA PARA LA PRÁCTICA DEL GOLF DESDE EL AÑO 1989, SUSTITUYENDO EL ANTIGUO USO COMO AERÓDROMO}

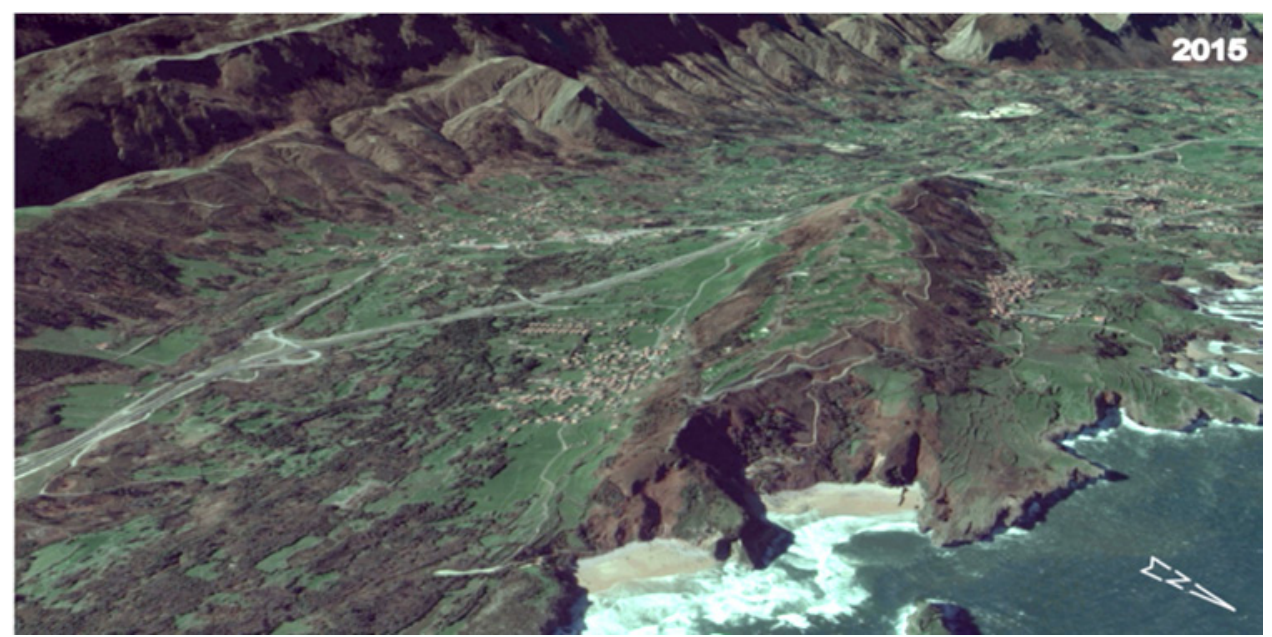

Fuente: Imagen de Google Earth.

Paralelamente, aprovechando el mismo género de recursos turísticos, han surgido rutas temáticas monográficas de iniciativa municipal que promueven el disfrute del paisaje. Entre las principales podemos mencionar la "Ruta Indiana", que recorre localidades agraciadas con residencias y equipamientos financiados por los exitosos emigrantes a América: La Borbolla (plaza pública y casonas), Pendueles (casonas y palacetes), Vidiago (escuelas y chalés), Purón (villa residencial), La Pereda (capilla, bolera y Castañedo), Parres (caserón), La Arquera (colegio), Llanes (casino, casas y palacios), Poo (casas, chalés, iglesia, cementerio, bolera y casino), Porrúa (chalé, finca, iglesia y casino), Balmori (chalés, fuente pública y lavadero), Posada (villa residencial), Naves (plaza y fuente públicas, residencias), Nueva (villa residencial). También destaca el itinerario "Llanes de Cine", que incardina veinticinco lugares costeros en los que se han filmado numerosas producciones de cine y televisión desde 1941, incluyendo playas, acantilados, caminos rurales, paseos urbanos, plazas públicas, palacios, capillas... (Ayuntamiento de Llanes, s.f. a y b; Millán Barroso, Rodríguez Pérez y Sevilla Álvarez, 2017). Otros itinerarios, promocionados desde el ámbito académico y científico, concretamente desde la Geología y la Geografía, y orientados a visitas con valor didáctico subrayan la singularidad del paisaje natural de este sector de la marina oriental, fuente de aprendizaje y disfrute estético (Ruiz Fernández, 2002; Díaz, Fernández, Bueno y Alonso, 2005; Adrados González, 2011 y 2014).

Además, otras actuaciones oficiales relacionadas con la valoración del paisaje han sido la construcción de miradores y el mantenimiento, la mejora y la ampliación de paseos, caminos y sendas. En el caso de los primeros, descubren la llamativa cercanía de mar y montaña en 
este territorio: por ejemplo, La Boriza (extremo oriental de la sierra plana de Cué, levantado en 1988). Respecto a los paseos, destaca la ampliación del paseo de San Pedro, en el acantilado de Llanes, así como la adecuación del Paseo de San Antón, entre el puerto y la playa de Puerto Chico, y de la Senda Fluvial del Río Carrocedo en la misma localidad de Llanes, además de la adecuación del itinerario que recorre todo el frente costero.

\section{Cuadro 3}

\section{PLAZAS Y ESTABLECIMIENTOS DE ALOJAMIENTO COLECTIVO, POR TIPOS, EN LLANES (2015)}

\begin{tabular}{|c|c|c|}
\hline Tipo/Categoría & $\mathrm{N}^{\circ}$ de plazas & $\mathrm{N}^{\circ}$ de establecimientos \\
\hline Hoteles 4 estrellas & 197 & 5 \\
\hline Hoteles 3 estrellas & 1.127 & 27 \\
\hline Hoteles 2 estrellas & 594 & 25 \\
\hline Hoteles 1 estrella & 199 & 9 \\
\hline Hostales & 48 & 1 \\
\hline Pensiones & 279 & 19 \\
\hline Hoteles rurales & 382 & 18 \\
\hline Casas de aldea & 942 & 128 \\
\hline Apartamentos rurales & 915 & 52 \\
\hline Camping & 7.419 & 8 \\
\hline Apartamento turístico & 1.310 & 51 \\
\hline Albergue & 530 & 9 \\
\hline Viviendas vacacionales & 778 & 135 \\
\hline TOTAL & 14.720 & 487 \\
\hline
\end{tabular}

Fuente: Sistema de Información Turística de Asturias, s.f. b.

Todo ello tiene reflejo en el alojamiento colectivo disponible, que se adapta a las visitas crecientes (cuadro III), superando el umbral de 50.000 visitantes en los últimos años. La última cifra registrada en Llanes, en 2017, asciende a 51.502 visitantes, que han contado a su disposición con 15.686 plazas de alojamiento (Ayuntamiento de Llanes, 2018).

\subsection{El desafío de la protección y conservación del paisaje en el contexto del desarro- llo turístico reciente}

Los valores y las cualidades de los elementos que dan forma al paisaje y configuran la imagen turística de Llanes han suscitado la atención de la Administración en lo concerniente a su protección oficial, si bien las acciones de protección y conservación se 
han planteado, en su mayoría, sobre lugares muy precisos y no abarcando al conjunto del territorio.

El Plan de Ordenación de los Recursos Naturales de Asturias (PORNA), aprobado en 1994, propone la declaración de cuatro Monumentos Naturales, localizados todos ellos en la rasa costera, de reducidas dimensiones y destacados por su singularidad, rareza y belleza. Se trata de la Playa de Gulpiyuri, los Bufones de Arenillas, el complejo de Cobijeru (incluye la playa de Las Acacias o de Cobijeru y la Cueva de Cobijeru) y el Bufón de Santiuste, todos ellos aprobados por Decreto en el año 2001.

La protección de elementos de carácter histórico y artístico es asimismo importante y más antigua, pero también de carácter puntual. Han sido numerosos los elementos declarados como Bien de Interés Cultural; por ejemplo, cuevas como las de El Quintanal y La Cuevona (Balmori), Cueto de la Mina, La Riera y El Tebellín (Bricia), La Herrería (La Pereda), El Covarón (Parres), Coberizas y Trescalabres (Posada) y Samoreli (Rales) -todas en 1985-; pinturas y grabados neolíticos en el Ídolo de Peña Tú (Puertas de Vidiago) en 1924; torres, palacios y casonas, como la Torre del Castillo (Llanes) en 1876, el Palacio de Espriella (Villahormes) en 1985, la Casa del Cercáu (Llanes) en 1991, el Palacio de Vega del Sella (Nueva) en 1991, el Palacio de Gastañaga (Llanes) en 1992 y la Torre de Tronquedo (Andrín) en 2003; construcciones religiosas en San Antolín de Bedón en 1931 y Santa María del Conceyu (Llanes) en 1993; y ejemplos de arquitectura indiana contemporánea como el Casino de Llanes, en 2006. Habría que añadir, además, los bienes comprendidos en el Inventario del Patrimonio Cultural de Asturias (principalmente arqueológicos y equipamientos de financiación indiana) y otros incluidos en los Catálogos Urbanísticos de Protección.

Han sido escasas, sin embargo, las actuaciones con implantación zonal, abarcando un espacio más amplio. Así, en el ámbito de la protección del patrimonio histórico-artístico, a escala de conjunto histórico, se puede mencionar la distinción del núcleo de Llanes en 1971. También es importante la inclusión del ramal costero del Camino de Santiago en la lista del Patrimonio Mundial de la UNESCO en 2015 y, en el terreno de la protección de la naturaleza, la delimitación de la Zona Especial de Conservación Río Purón, la Zona Especial de Conservación Ría de Ribadesella-Ría de Tinamayor, la Zona de Especial Conservación de Río Las Cabras-Bedón y la Zona de Especial Conservación de la Sierra Plana de la Borbolla en la red europea Natura 2000 (Principado de Asturias, s.f. c).

Atendiendo a la dinámica más reciente del paisaje de la marina oriental parece evidente que únicamente la regulación de usos en lugares muy concretos y especialmente frecuentados, cuestión que persigue la figura de monumento Natural, no da respuesta al desafío que supone conciliar la conservación del medio natural con el desarrollo turístico. En este sentido, conviene recordar que en el aludido instrumento de ordenación de los recursos natural aprobado en 1994 sí se proponía, si bien todavía no ha llegado hacerse efectiva su declaración, la creación en este ámbito de dos Paisajes Protegidos: el Paisaje Protegido de la Sierra del Cuera y el Paisaje Protegido de la Costa Oriental; dichas figuras de protección, aunque en cierto modo menos exigente y restrictiva que otras como pueden ser los parques naturales o las reserva naturales, sí atienden a los valores estéticos y culturales del espacio y abarcan además sectores más amplios. 
Así, en el caso de la descripción del espacio incluido en el Paisaje Protegido de la Costa Oriental, se destacan muy particularmente la organización del relieve, con su multitud de niveles de arrasamiento marino (hasta seis desde el mar hasta las estribaciones del Cuera), la variedad litológica, coexistiendo cuarcitas y calizas, y las formas de modelado características en este contexto geológico, muy diversas, algunas complejas y de singular belleza, desde las vertientes regularizadas y planicies de los llanos o sierras planas hasta toda la variedad resultante de la disolución kárstica en las áreas próximas a la costa ("mosaicos" de cuetos y depresiones kársticas, castros, tómbolos, simas, bufones...). La Administración Autonómica, en el momento en que se redactó el mencionado documento de ordenación (PORNA), entendía que era necesario poner en marcha una figura de protección que reconociese la belleza y constituyera, a la vez, una garantía frente al reclamo que suponía este valor paisajístico, con el fin de regular los usos turísticos y residenciales, de modo que el desarrollo de estos subsectores económicos y la protección del paisaje fuesen compatibles (Principado de Asturias, s.f. a).

En cuanto al Paisaje Protegido de la sierra del Cuera, el Principado defendía motivos similares dado que la configuración del relieve se sitúa en el núcleo de la argumentación. Por su volumen, disposición, verticalidad y proximidad a la costa, la sierra es considerada un elemento determinante en el paisaje y condicionante del poblamiento y los usos del suelo. Se destaca aquí también la litología, pues de su naturaleza calcárea resulta un modelado kárstico importante incluso en la zona de cumbres (lapiaces, dolinas, uvalas, poljés, valles ciegos, simas...). En la base y hacia el norte se destacan algunas sierras planas cuartíciticas próximas al eje de la sierra (Principado de Asturias, s.f. b).

Con las actuaciones oficiales señaladas, y permaneciendo sin declarar estos dos Paisajes Protegidos (con un nivel de protección que parece, por lo demás, insuficiente), la presión urbanística y la pérdida de calidad del paisaje se han acrecentado en tiempo reciente, sobre todo en el área próxima a la línea de costa. Únicamente han contenido esta tendencia y ejercido la función de herramientas para la protección algunas determinaciones e instrumentos en el ámbito de la ordenación del territorio, siendo esenciales la elaboración del Plan Territorial Especial de Ordenación del Litoral Asturiano (POLA) y la aplicación generalizada a todo el litoral, con excepción de las áreas urbanas, de la figura de Suelo No Urbanizable de Costas.

Cabe destacar que el POLA, aprobado por la Comisión de Urbanismo y Ordenación del Territorio de Asturias (CUOTA) en mayo de 2005, introduce en su texto propuestas para resolver la disyuntiva rígida que supone optar entre las medidas restrictivas de conservación ambiental y paisajística o el disfrute de la ciudadanía en ese entorno. Se trata de programas de actuación que apuestan por el criterio de mínima intervención y máxima integración en el paisaje (Carrero de Roa, 2008). Uno de ellos ha consistido en la articulación de una senda que aprovecha la densa red de caminos vecinales preexistentes, desechándose la alternativa de construir un nuevo trazado. Las obras permitidas se limitan al mantenimiento, drenaje y mejora del firme, aparte de la señalización y la habilitación de pequeños miradores. Con este programa se facilita el acceso peatonal a los parajes de especial interés, como acantilados, playas, núcleos costeros, monumentos, zonas arqueológicas, etc. (Carrero de Roa, 2008; Principado de Asturias, 2005). 
Por otro lado, resulta digna de mención la propuesta de "parques-playa" para las zonas de baño de Cuevas del Mar, San Antolín de Bedón y Niembro (Principado de Asturias, 2005). Esta figura persigue un aprovechamiento racional del litoral en las épocas de mayor presión turística, procurando una acogida ordenada y adecuada a la fragilidad de los ecosistemas de costa. Se plantea restringir el paso de vehículos privados a las áreas anexas a las playas para atenuar el impacto ambiental y paisajístico, desviando el tránsito rodado hacia zonas situadas a una distancia razonable, que pueda ser recorrida a pie. En este programa de actuación también se propone habilitar zonas recreativas y de servicios básicos (aseos, venta de bebidas, botiquín, duchas...) próximas a las playas, pero cuidando de alejar los impactos (Carrero de Roa, 2008). Además, esta medida tiene en cuenta el carácter estacional de la demanda y prevé dos tipos de parques: "permanente" con mobiliario urbano fijo y aparcamientos con mayor capacidad (requieren, por tanto, expropiaciones de terrenos); y "de temporada", que compagina el uso agrario de los titulares de las parcelas con el arrendamiento para fines recreativos en períodos de mayor afluencia de visitantes.

Entre las actuaciones en el ámbito de la ordenación del territorio y con vocación de protección del litoral surge más recientemente otro instrumento autonómico denominado Plan Territorial Especial del Suelo No Urbanizable de Costas (PESC), aprobado en septiembre de 2016. Este documento, que constituye uno de los diferentes desarrollos que propone el aludido POLA (Plan Especial del Suelo de Costas), tiene por cometido la salvaguarda y la consolidación de una imagen de excelencia del litoral sin menoscabo del desarrollo de la actividad económica. Para ello, dentro de la franja de Suelo No Urbanizable de Costas categorizado ya por el POLA, se acomete una zonificación y la delimitación de enclaves para terrenos que, por sus características, son susceptibles de una consideración específica. Pueden establecerse así una regulación y medidas de protección adaptadas, según se trate de ámbitos con riqueza geológica, zoológica, botánica y paisajística, particularmente aptos para la actividad agraria, etc.

Además, se catalogan todas las construcciones del suelo no urbanizable de costas fuera de los núcleos rurales para determinar su categoría dependiendo del valor cultural, el interés arquitectónico, la morfología, la ubicación y la integración paisajística. Con ello se distinguen entidades protegidas (las de mayor valor y singularidad), integradas (respondiendo a la tipología tradicional), compatibles (con rasgos aceptables e impacto asumible) y de impacto elevado, siendo distinto, en consecuencia, el grado de obra y reforma posible en cada caso. El cambio de uso en la edificación (de residencial a turístico o asistencial, por ejemplo) se permite ahora (antes no era posible) si se adecua al tipo de obras y al grado de reforma permitido en cada caso (Principado de Asturias, 2014)

Con todo, no parece suficiente reformular y articular políticas autonómicas sectoriales junto a las territoriales integrales. Desde la esfera institucional es necesaria una coordinación eficiente entre las determinaciones autonómicas y las tomadas por el planeamiento local, siendo muchas veces estas últimas contrarias a los principios de equilibrio territorial y sostenibilidad. Un ejemplo claro está en la previsión recogida en el Plan General de Ordenación de Llanes, redactado durante la década pasada, de crear diversas bolsas de suelo urbanizable y ejecutar actuaciones urbanísticas mediante Planes Parciales junto a la costa. En este contexto se produjo la aprobación del Plan Parcial de La Talá, al oeste 
de la Villa de Llanes (no lejos del paseo De San Pedro), que planteaba construir varios centenares de viviendas en un espacio inmediato a la línea de costa, declarado como LIC y ZEPA (figura 7).

Posteriormente, el Plan General fue anulado por el Tribunal Supremo, hecho que prolongaba los problemas del municipio con la redacción y aplicación de sus documentos de planeamiento. Los dos planes anteriores, elaborados en las décadas de los años ochenta y noventa, habían sido igualmente anulados, principalmente por cuestiones formales y de procedimiento, sin que los aspectos ambiental y paisajístico fueran suficientemente subrayados (Rodrigo, 2010; Cea, 2013).

En respuesta a este género de actuaciones, resulta de interés el trabajo creciente de colectivos locales para la protección del patrimonio llanisco y la defensa de los intereses comunes de los vecinos en aspectos urbanísticos, medioambientales, culturales, etc, destacando el colectivo Agrupación de Vecinos y Amigos de Llanes (AVALL), entre otros muchos de núcleos y parroquias del territorio analizado. Se trata de movimientos apoyados en la consideración del paisaje como reflejo de modos de vida y memoria del territorio; un bien a salvaguardar de transformaciones impulsadas por voluntades muchas veces externas a la colectividad local y que responden a dinámicas económicas poco sensibles con los rasgos propios de la zona, a menudo conducentes a la homogeneización o a la banalización paisajística (Hernández Hernández, 2009). Precisamente, ante esta contestación asociativa y popular, la posterior elaboración de documentos de planeamiento urbanístico ha pretendido integrar la participación de asociaciones vecinales y de distintos sectores de actividad económica en el debate, al tiempo que velar por el respeto medioambiental (Toraño 2011). No se ha alcanzado, sin embargo, un resultado satisfactorio; así ha ocurrido con el Plan General de Ordenación (PGO) elaborado en Llanes en la primera mitad de la presente década y anulado en el mismo año de su aprobación (2015) debido a un cambio de gobierno municipal, al encontrarse los colectivos ciudadanos más arriba señalados, ahora constituidos como partido político, entre los nuevos regidores (Díaz, 2012 y 2015; Cea, 2014 y 2015).

Pese a las intenciones iniciales, el modelo territorial de este último documento desestimado no protegía el medio ambiente ni la calidad del paisaje, dado que fomentaba la expansión residencial y la presión urbanística, al menos desde la opinión de la Agrupación de Colectivos Asturianos (Díaz, 2012); ejemplo de ello son la intensificación urbanizadora prevista en el eje Niembro-Barro-Celorio o el número de nuevas viviendas proyectadas en el documento, alrededor de 12.000 (Díaz, 2012 y 2015; Cea, 2014 y 2015). Desde 2016 se trabaja en un nuevo proyecto de Plan General, lanzado por el equipo de gobierno actual, que pretende priorizar el consenso entre todos los agentes implicados, evitar la masificación del turismo residencial, así como atender los principios de preservación de los rasgos territoriales singulares y defensa del patrimonio (Díaz, 2015; Cea, 2016 y 2017). El encargo de un estudio sobre el valor del paisaje en la definición del modelo territorial del municipio a un equipo de referencia con prestigio reconocido en el ámbito internacional (Mata y Ferrer, 2016) supone un paso expresivo y sensible. 
Figura 7

IMAGEN REPRESENTATIVA DE LA INCIDENCIA DEL PROCESO URBANIZADOR ASOCIADO A LA PRESIÓN TURÍSTICA EN EL ENTORNO DE LA VILLA DE LLANES: EL RECUADRO SUPERIOR CORRESPONDE AL SUPRIMIDO PLAN PARCIAL DE LA TALÁ Y EL INFERIOR MUESTRA EL AVANCE DE LA URBANIZACIÓN EN LA PORTILLA Y PANCAR
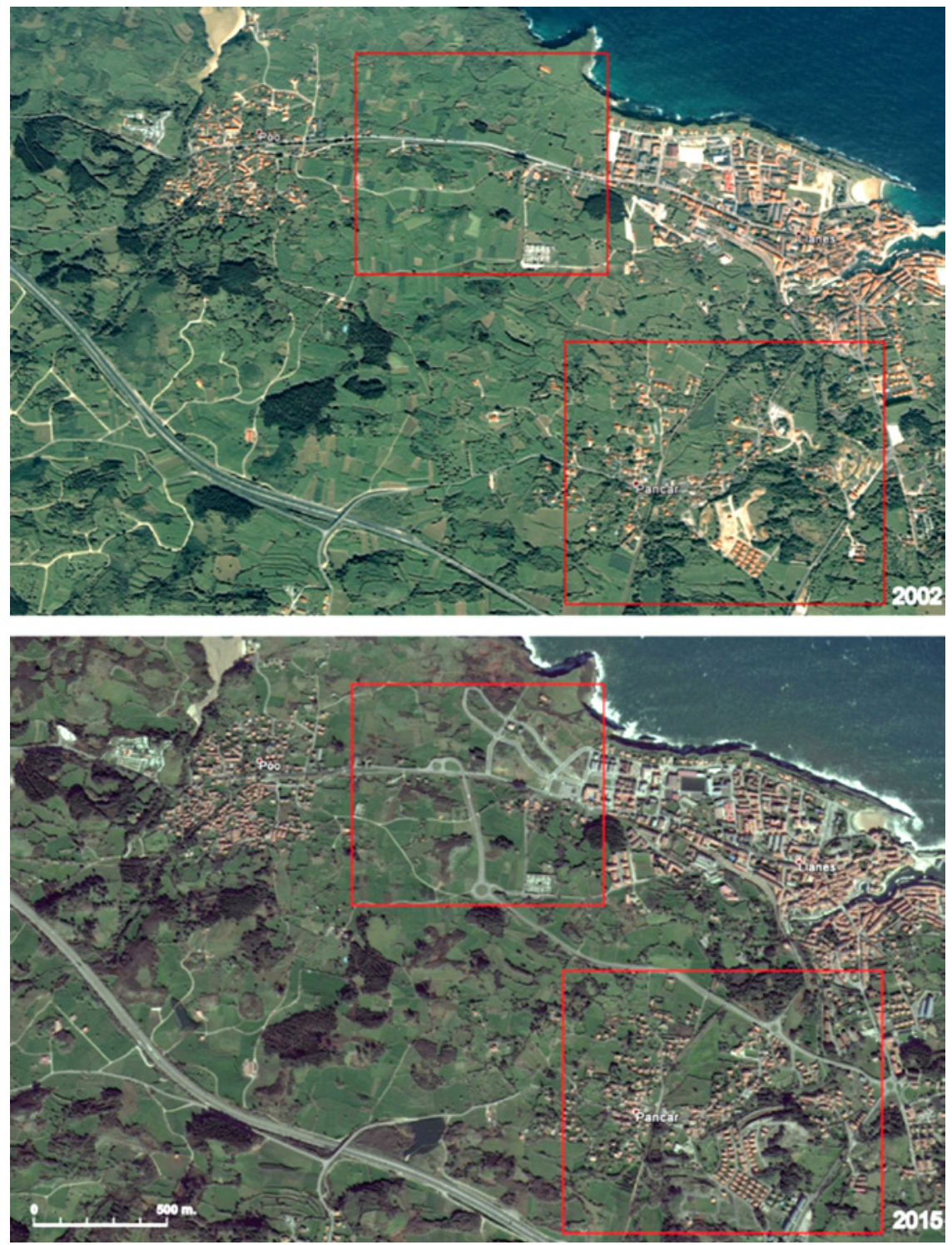

Fuente: Imágenes de Google Earth. 


\section{A MODO DE CONCLUSIÓN: HACIA UNA VALORIZACIÓN EQUILIBRADA}

El paisaje es un elemento esencial dentro del conjunto de rasgos con que Llanes alimenta su desarrollo turístico. Sin embargo, vinculados al aprovechamiento del paisaje como recurso, tienen lugar algunos procesos económicos y cambios territoriales que ponen en riesgo la conservación de los valores originales que construyen la reputación de este espacio costero.

Basta pensar en el impulso de la promoción inmobiliaria, opuesto al mantenimiento de una imagen de calidad del litoral. La extensión del espacio construido, a menudo con densidades de ocupación, volúmenes, estilos y materiales disonantes irrumpe de manera discordante entre los elementos y conjuntos patrimoniales, desdibujando los entornos históricamente apreciados (Morales, 2011). Tampoco ayudan la deficiente adaptación y la estética discutible de algunos establecimientos de servicios, o la insuficiente planificación de accesos rodados. En algunos espacios más frágiles, conviene apoyar decididamente el uso peatonal de caminos tradicionales frente al desplazamiento a motor y al empleo de aparcamientos improvisados o mal planificados (Fernández (dir.), Olay, Sevilla y Liébana, 2011). En este sentido, es de agradecer que las propuestas incluidas en instrumentos de ordenación territorial de alcance autonómico, como el POLA y el PESC, atiendan este problema con un criterio coherente.

Por todo lo comentado, parece adecuado inclinarse por una vocación turística racional, que anteponga la calidad a la cantidad en aspectos clave como la explotación de recursos, el diseño y la oferta de productos o el perfil de los visitantes. Y si se tiene en cuenta que, en esta zona, como en otras del Noroeste peninsular (por ejemplo, Sanxenxo en Pontevedra, Laredo o Castro Urdiales en Cantabria...), la afluencia de turistas en determinadas fechas supone ya inconvenientes que abren el debate sobre los efectos del turismo, debe apelarse tanto a la responsabilidad pública institucional como al criterio de la ciudadanía, no siempre resueltos con acierto.

Las acciones oficiales lanzadas bajo figuras de protección de la Comunidad Autónoma requieren una evaluación permanente. Son, en buena parte, protecciones de lugares concretos que sí reciben, en áreas muy localizadas, amparo institucional para la salvaguarda de valores ecológicos, estéticos, históricos, etc. Pero no abarcan todo el territorio que merece atención. Y en el caso de la figura que parece dirigirse más específicamente al cuidado del paisaje en áreas amplias, la de Paisajes Protegidos, no se ha hecho efectiva ni parece diseñada para preservar suficientemente de los procesos que generan riesgos (Fernández y Sevilla, 2013). La propia Administración autonómica recomienda la figura de Paisaje Protegido para espacios en los que no se perciban problemas de conservación graves ni incompatibilidades mayores de usos del suelo y actividades económicas, situación que no se da en la zona de estudio, sometida a fuertes presiones urbanísticas. De ahí que sean necesarias, como complemento a las protecciones de la ordenación sectorial medioambiental, las determinaciones de los instrumentos autonómicos de ordenación territorial integral, señaladas más arriba y en el apartado anterior. Aunque también es imprescindible la compleja coordinación con el planeamiento urbanístico de ámbito municipal, del que emanan, a menudo, soluciones y medidas contrapuestas a las de las restantes escalas administrativas. 
En el desarrollo de la actividad turística de la costa oriental de Asturias sería oportuno, además, un planteamiento inspirado en los principios del Convenio Europeo del Paisaje, aprobado en 2000. Se trataría de aplicar la iniciativa comunitaria que impulsa el compromiso de protección, ordenación y gestión del paisaje, conforme a una serie de medidas estipuladas en el Convenio, por parte de las administraciones públicas competentes, con la colaboración de la sociedad civil y las entidades privadas; lo que supondría coordinar a instituciones implicadas en las políticas territorial, medioambiental, cultural, económica y social, todas ellas con potencial repercusión en el paisaje (Panadero Moya, García González y Panadero Alarcón, 2011).

Este documento oficial europeo alberga una perspectiva que puede orientar el nexo entre las acciones de los diversos departamentos de la Administración y los agentes económicos y sociales, persiguiendo objetivos comunes: si el paisaje constituye un bien público a conservar, merecen la pena iniciativas turísticas dirigidas a un público que anteponga la autenticidad, la originalidad y la experiencia de aprendizaje en el destino.

\section{BIBLIOGRAFÍA}

ADRADOS GONZÁLEZ, L. (2014): "Experiencia didáctica en un área de alto valor patrimonial: el karst litoral del oriente de Asturias. Enseñanza de las ciencias de la tierra", Revista de la Asociación Española para la Enseñanza de las Ciencias de la Tierra, vol. 22, n 1, pp. 49-60.

ADRADOS GONZÁLEZ, L. (2011): Costa oriental de Asturias. Un paisaje singular. Oviedo, Adrados Ediciones.

AGUILAR AGUILAR, A., PALAFOX MUÑOZ, A. y ANAYA ORTIZ, J.S. (2015): “El turismo y la transformación del paisaje natural", Revista de Ciencias Sociales y Humanidades, vol. 24, $\mathrm{n}^{\circ} 47$, pp. 19-20.

ALEDO TUR, A. (2008): "De la tierra al suelo: la transformación del paisaje y el nuevo turismo residencial”, Arbor. Ciencia, Pensamiento y Cultura, vol. CLXXXIV, no 729 , pp. 99-113

ÁLVAREZ MARTÍNEZ, M.S. (2015): “El arte como recurso: intervenciones escultóricas y propuestas artísticas en la regeneración de las villas costeras asturianas", Ábaco. Revista de Cultura y Ciencias Sociales, no 80-81, pp. 41-47.

ALVARGONZÁLEZ RODRÍGUEZ, R.M. (1997): "La Marina oriental”, en Asturias. Montes y Valles. Gijón, El Comercio, pp. 53-64.

AYUNTAMIENTO DE LLANES (2018): Información estadística. Llanes, Oficina de Turismo.

AYUNTAMIENTO DE LLANES (2008): Estudio para la formulación de iniciativas turístico pesqueras en el municipio de Llanes. Documento técnico. Ayuntamiento de Llanes, Universidad Politécnica de Madrid, Consejería de Industria y Empleo del Principado de Asturias.

AYUNTAMIENTO DE LLANES (1995): Convenio marco de colaboración para la implantación de un Plan de Excelencia Turística. Documento técnico.

AYUNTAMIENTO DE LLANES (s.f. a): Llanes de cine, publicación web. Disponible en http://www.llanesdecine.com/ 
AYUNTAMIENTO DE LLANES (s.f. b): Ruta indiana, publicación web. Disponible en http://www.llanes.com/sites/default/files/RUTA\%20INDIA-NA_0.pdf

BELLMUNT, O. y CANELLA, F. (1899): Guía General del Viajero en Asturias. Gijón, Fototipia y Tipografía de Octavio Bellmunt y Cia.

BLANCO CASTRO E. et al. (1998): Los bosques ibéricos. Una interpretación geobotánica. Barcelona, Planeta.

CALliZO, J. (1993): "El turismo", en Geografía General (Tomo II). Madrid, Taurus, pp. 326-344.

CAMPO FRANCÉS, A del. (1972): "El sentimiento estético, soporte subjetivo del turismo (el paisaje)", Estudios Turísticos, no 36, pp. 239-246.

CÁNOVES, G., VILlARINO, M., ARMAS, P., SEGUí, M., et al. (2002): El patrimonio paisajístico como producto de consumo de turismo rural: casuísticas regionales", en Actas del XI Coloquio de Geografía Rural. Santander, Asociación de Geógrafos Españoles, pp. 69-78.

CARRERO DE ROA, M. (2008): "Los nuevos usos del suelo en el litoral asturiano: El marco de la planificación: El POLA", en Los nuevos usos del suelo en el litoral asturiano. Oviedo, Universidad de Oviedo, pp. 59-75.

CEA, E.G. (2017): "Llanes pretende aprobar en 2019 el Plan General que hoy comienza a redactarse", La Nueva España, 11 de octubre de 2017. Disponible en http://www.lne. es/oriente/2017/10/11/llanes-pretende-aprobar-plan-general/2176249.html

CEA, E.G. (2016): "Llanes inicia el proceso de participación ciudadana del nuevo Plan General”, La Nueva España, 29 de junio de 2016. Disponible en http://www.lne.es/ oriente/2016/06/29/1lanes-inicia-proceso-participacion-ciudadana/1949453.html

CEA, E.G. (2015): "El PSOE aprueba en solitario el Plan General de Llanes, que rechaza toda la oposición”, La Nueva España, 25 de febrero de 2015. Disponible en http:// www.Ine.es/oriente/2015/02/25/psoe-aprueba-solitario-plan-general/1718369.html

CEA, E.G. (2014): "La oposición tacha de excesivo el número de pisos proyectados por el PSOE y duda que el documento esté listo para 2015", La Nueva España, 4 de septiembre de 2014. Disponible en http://www.Ine.es/oriente/2014/09/04/constructoresven-barbaridad-4000-viviendas/1637445.html

CEA, E.G. (2013): "Los expertos consideran imposible que Llanes tenga un PGO antes de 2015", La Nueva España, 30 de junio de 2013. Disponible en http://www.lne.es/ oriente/2013/06/30/expertos-consideran-imposible-llanes-tenga/1435264.html

DELGADO MARTINEZ, A.M. y PANTOJA TIMARAN, F. (2016): "Valoracion del paisaje en una propuesta de turismo sostenible: la "Ruta del Oro", Narino (Colombia)", Cuadernos de Geografía: Revista Colombiana de Geografía, $\mathrm{n}^{\circ} 25$ (1), pp. 233-253.

DELGADO VIÑAS, C., GIL DE ARRIBA, C., HORTELANO MÍNGUEZ, L.A. y PLAZA GUTIÉRREZ, J.I. (2007): Dinámica territorial y transformación del paisaje en la montaña cantábrica. Salamanca, Plaza Universitaria Ediciones.

DÍAZ, R. (2015): "Llanes, un culebrón urbanístico sin fin", La Nueva España, 20 de septiembre de 2015. Disponible en http://www.Ine.es/oriente/2015/09/19/1lanes-culebronurbanistico/1815504.html

DÍAZ, R. (2012): "La Agrupación de Colectivos Asturianos tilda el Plan de Llanes de "insulto a la inteligencia", La Nueva España, 14 de abril de 2012. Disponible 
en http://www.lne.es/oriente/2012/06/13/agrupacion-colectivos-asturianos-tilda-planllanes-insulto-inteligencia/1227568.html

DÍAZ, T.E., FERNÁNDEZ, J.A., BUENO, A. Y ALONSO, J.I. (2005): Itinerario botánico por el oriente de Asturias. El paisaje vegetal de los Lagos de Covadonga (Parque Nacional de los Picos de Europa) y de los Bufones de Pría (Acantilados de Llanes). Gijón, Ediciones Trea.

ESPEJO MARÍN, C. (2011): “El paisaje como recurso turístico»”, en Retos y perspectivas de la gestión del paisaje en Canarias. Santa Cruz de Tenerife, Gobierno de Canarias y Observatorio del Paisaje de Canarias, pp. 437-462.

FERNÁNDEZ, F. Y SEVILLA, J. (2013): "El paisaje del sector costero del extremo oriental de Asturias", en Atlas de los paisajes agrarios de España. Madrid, Ministerio de Agricultura, Alimentación y Medio Ambiente, pp. 363-370.

FERNÁNDEZ GARCÍA, F. (Dir.), OLAY VARILLAS, D., SEVILLA ÁLVAREZ, J. LIÉBANA DÍAZ, E. (2011): El paisaje agrario. Un bien público producido por los campesinos y a conservar mediante una planificación y gestión integral (Tomo I). Informe técnico. Consorcio para el Desarrollo Rural del Oriente de Asturias, Universidad de Oviedo, Mancomunidad del Oriente de Asturias y Saja-Nansa Asociación de Desarrollo Rural. Financiado por el Ministerio de Medio Ambiente y Medio Rural y Marino.

FERNÁNDEZ GARCÍA, F. y QUIRÓS LINARES, F. (2001): Atlas aéreo de Asturias. Oviedo, Editorial Prensa Asturiana.

FERNÁNDEZ SALINAS, V. (2013): “Los paisajes de interés cultural de Asturias”, Ería. Revista Cuatrimestral de Geografía, nº 91, pp. 129-149.

FERRER REGALES, M. (1960): La región costera del oriente asturiano, estudio geográfico. Oviedo, Instituto de Estudios Asturianos.

FLOR RODRÍGUEZ, G. (1983): "Las rasas asturianas: ensayos de correlación y emplazamiento", Trabajos de Geología, no 13, pp. 65-81.

FORONDA, M. DE (1885): "De Llanes a Covadonga. Excursión geográfico-pintoresca”, Boletín de la Sociedad Geográfica de Madrid, Año X, nº 3, marzo de 1885, pp. 145185.

FROCHOSO, M. CASTAÑÓN, J.C. (1990 a): "El medio natural (I): los rasgos generales", en Historia de Asturias, vol.1. Oviedo, Editorial Prensa Asturiana, pp. 1-16.

FROCHOSO, M. y CASTAÑÓN, J. C. (1990 b): "El medio natural (II): Las unidades básicas", en Historia de Asturias, vol. 1. Oviedo, Editorial Prensa Asturiana, pp. 17-32.

GOBIERNO DE ESPAÑA (1971): "Decreto 1021/1971, de 22 de abril, por el que se declara Conjunto Histórico-Artístico la villa de Llanes (Asturias)", Boletín Oficial del Estado, ${ }^{\circ} 112,11$ de mayo de 1971, pp. 7.555-7.556.

GUTIÉRREZ MAYO, J. y ÁLVAREZ URÍA, G. (1905): Guía General de Asturias para 1905. Gijón, Compañía Asturiana de Artes Gráficas.

HERNÁNDEZ HERNÁNDEZ, M. (2009): "El paisaje como seña de identidad territorial: valorización social y factor de desarrollo, ¿utopía o realidad?”, Boletín de la Asociación de Geógrafos Españoles, n 49, pp. 169-183.

LAGUNA MARÍN-YASELI, M. y NOGUÉS BRAVO, D. (2001): “La potencialidad turística del medio natural en el LIC de las sierras ibéricas riojanas mediante evaluación multicriterio", Zubía Monográfico, $n^{\circ} 13$, pp. 227-240. 
LOIS GONZÁLEZ, R.C., PIÑEIRA MANTIÑÁN, M.J. y SANTOMIL MOSQUERA, D. (2009): "Imagen y oferta de alojamiento en el medio rural de Galicia", Revista Galega de Economía, vol. 18, no 2, pp. 71-90.

LOIS GONZÁLEZ, R.C., PIÑEIRA MANTIÑÁN, M.J. y SANTOMIL MOSQUERA, D. (2010): "La imagen del rural en la promoción turística de Galicia”, Oceánide, nº 2, p. 3.

LLANO ROZA DE AMPUDIA, A. del (1928): Bellezas de Asturias, de Oriente a Occidente. Oviedo, Diputación Provincial, Imprenta Gutenberg.

MADERA GONZÁLEZ, M.E. y ROMERO LÓPEZ, D. (1992): “La Marina Oriental Asturiana: Llanes y Ribadedeva", en Geografía de Asturias. Oviedo, Editorial Prensa Asturiana, pp. 265-284.

MARY, G. (1979): Évolution de la bordure côtière asturienne (Espagne) du Neogène à l'actuel. Thèse de Doctorat d'État (inédita), Universidad de Caën, 3 vols.

MARY, G. (1983): "Evolución del margen costero de la Cordillera Cantábrica en Asturias desde el Mioceno", Trabajos de Geología, no 13, pp. 3-35.

MATA OLMO, R. (Dir.) y FERRER JIMÉNEZ, D. (Coord.) (2016): Estudio y estrategia de paisaje para la definición del modelo territorial del concejo de Llanes. Llanes, Fundación de la Universidad Autónoma de Madrid, Ayuntamiento de Llanes.

MILLÁN BARROSO, P.J., RODRÍGUEZ PÉREZ, C. y SEVILLA ÁLVAREZ, J. (2017): "El paisaje en la producción cinematográfica: la costa de Llanes según José Luis García”, Liño. Revista Anual de Historia del Arte, no 23, pp. 159-174.

MONMARCHÉ, M (Dir.) (1927): Espagne. Les Guides Bleus. París, Hachette.

MORALES, M.C. (2012): "La remodelación intensiva de los puertos históricos de Asturias: consecuencias urbanísticas y patrimoniales", en Paisajes modelados por el agua: entre el arte y la ingeniería. Mérida, Editora Regional de Extremadura, pp. 143-157.

MORALES, M.C. (2011): "Une ville américaine sur la côte cantabrique d'Espagne", en Les Villes et le monde. Du moyen Âge au XXè siècle. Rennes, Presses Universitaires de Rennes, pp. 351-369.

MORALES, M.C., ÁlVAREZ, E. y VALLE, F. (2003): Ayuntamiento de Llanes. 18622003, tres siglos de memoria. Llanes, Excelentísimo Ayuntamiento de Llanes.

MORALES SARO, M.C. (1999): Llanes y América. Cultura, arte y sociedad. México D.F., Editorial Porrúa.

MUÑOZ JIMÉNEZ, J. (1982): “Geografía física. El relieve, el clima y las aguas”, en Geografía de Asturias, tomo 1. Oviedo, Ayalga.

ORMAETXEA, O. y LUCIO, J.V. DE (1992): "Valoración de la calidad del paisaje vasco por la población. Métodos para su consideración objetiva como criterio de conservación", Cuadernos de Sección Historia, n 20, pp. 491-504.

PANADERO MOYA, M., GARCÍA GONZÁLEZ, J.A., y PANADERO ALARCÓN, J.D. (2011): "Paisaje y turismo. El corredor bético de Alcaraz (Albacete)", Cuadernos de Turismo, $\mathrm{n}^{\circ} 27,679-700$.

PÉREZ Y PIMENTEL, A. (1925): Asturias, paraíso del turista, Gijón, Talleres Tipográficos Editorial Covadonga.

PRINCIPADO DE ASTURIAS (2014): "El pleno de la CUOTA acuerda por unanimidad la aprobación inicial del Plan Especial del Suelo No Urbanizable de Costas", Actualidad del Gobierno del Principado de Asturias, 21 de julio de 2014. Disponible en https:// 
www.asturias.es/portal/site/webasturias/menuitem.6282925f26d862bcbc2b3510f2300 030/?vgnextoid=ab0b319fda857410 VgnVCM10000098030a0aRCRD

PRINCIPADO DE ASTURIAS (2005): “Acuerdo de 23 de mayo de 2005, adoptado por el Pleno de la Comisión de Urbanismo y Ordenación del Territorio de Asturias (CUOTA), relativo a la aprobación definitiva del Plan Territorial Especial de Ordenación del Litoral Asturiano (POLA)". Boletín Oficial del Principado de Asturias, Suplemento al B.O.P.A., nº 197 de 25 de agosto de 2005, pp. 1-175.

PRINCIPADO DE ASTURIAS (s.f. a): Paisaje Protegido de la Costa Oriental, Documento de trabajo / publicación web. Disponible en http://www.asturias.es/medioambiente/ articulos/ficheros/Paisaje\%20Protegido\%20de\%201a\%20Costa\%20Oriental_noPW. pdf

PRINCIPADO DE ASTURIAS (s.f. b): Paisaje Protegido de la Sierra del Cuera, documento de trabajo / publicación web. Disponible en http://www.asturias.es/ medioambiente/articulos/ficheros/Plantilla\%20Paisaje $\% 20$ Protegido $\% 20 \mathrm{de} \% 201 \mathrm{a} \% 20$ Sierra\%20de1\%20Cuera_noPW.pdf

PRINCIPADO DE ASTURIAS (s.f. c): Programa de Turismo Sostenible del Principado de Asturias 2020. Documento técnico.

QUIRÓS LINARES, F. y RODRÍGUEZ PÉREZ, C. (1998): "El medio físico”, en El Principado de Asturias. Oviedo, Ediciones Nobel, pp. 26-29.

RIVERA MATEOS, M. (2015): “Turismo experiencial y gestión estratégica de recursos patrimoniales: un estudio exploratorio de percepción de productos turísticos en las Sierras Subéticas cordobesas", Scripta Nova: Revista Electrónica de Geografía y Ciencias Sociales, 19: 511.

RODRIGO, M. (2010): "El Plan Urbano de Llanes anulado por el juez ni siquiera entró en vigor, según el Supremo", La Nueva España, 22 de octubre de 2010. Disponible en http://www.Ine.es/oriente/2010/10/22/plan-urbano-llanes-anulado-juez-siquiera-entrovigor-supremo/983848.html

ROMERO LÓPEZ, D. (1984): “Tipología de formas kársticas y relaciones morfoestructurales en la marina oriental asturiana", Ería, n ${ }^{\circ} 7$, pp. 119-133.

ROMERO LÓPEZ, D. y SENDÍN GARCÍA, M. A. (1986): "El karst litoral del Oriente asturiano y su aprovechamiento humano", Ería, no 10, pp. 123-126.

RUIZ FERNÁNDEZ, J. (2002): "Recursos didácticos en Geografía Física: itinerario pedagógico sobre el paisaje natural del oriente de Asturias", Espacio, Tiempo y Forma. Serie VI, Geografía, Tomo 15, pp. 147-166.

SALINAS CHÁVEZ, E. y MATEO RODRÍGUEZ, J. (1993): "La capacidad de carga de los paisajes: su análisis y evaluación para el turismo", Geosul, n 16 , Año VII- $2^{\circ}$ semestre, pp. 7-29.

SARO ROJAS, J (1985): Pequeñas Jornadas, Temas Llanes, $\mathrm{n}^{\circ} 28$ : Llanes, El Oriente de Asturias.

SISTEMA DE INFORMACIÓN TURÍSTICA DE ASTURIAS (s.f. a): El turismo en el municipio de Llanes en 1997. Gijón, Universidad de Oviedo. Disponible en http:// www.sita.org/contenedorGeneral.html?n=http://www.sita.org/informes/llanes97/index. htm 
SISTEMA DE INFORMACIÓN TURÍSTICA DE ASTURIAS (s.f. b): Series del turismo en Asturias. Resultados anuales concejos. Gijón, Universidad de Oviedo. Disponible en http://www.sita.org/seriesdeturismo.html

TORAÑO, M. (2011): "Llanes llama a los colectivos locales a que ayuden a redactar un nuevo Plan General", La Nueva España, 30 de noviembre de 2011. Disponible en http://www.Ine.es/oriente/2011/11/30/llanes-llama-colectivos-locales-ayuden-redactarnuevo-plan-general/1164144.html

ULRICH, R.S. (1983): “Aesthetic and Affective Response to Natural Environment", en Behavior and the Natural Environment. New York, Plenum Press, pp. 85-125.

VERA REBOLLO, F. (Coord.) (1997): Análisis territorial del turismo: una nueva geografía del turismo. Barcelona, Editorial Ariel.

VERA REBOLLO, F. (1992): “Turismo y crisis agraria en el litoral alicantino", en Los mitos del turismo. Madrid, Endymion, pp. 241-299.

VITAL, L. (1958): Relación del primer viaje de Carlos V a España por el cronista Lorenzo Vital (capítulos XXXII-XL). Oviedo, Instituto de Estudios Asturianos.

WIGRAM, E.T.A. (1906): Northern Spain. Londres, Adam\&Charles Black.

ZUBE, E.H., SELL, J.L. y TAYLOR, J.G. (1982): "Landscape Perception: Research, Application and theory", Landscape Planning, vol. 9 (1), pp. 1-33. 
